\title{
'...So yeah, you do what you can...'? \\ Exploring the barriers \\ to women's opportunities for physical activity
}

By

Marilyn Colleen Northcott

\author{
A thesis \\ Submitted in partial fulfillment \\ of the requirements for the Degree of \\ M.A. (Applied) in Social Science Research
}

Victoria University of Wellington

2009 


\begin{abstract}
This research was prompted by the Sport and Recreation New Zealand (SPARC) survey study Obstacles to Action: A study of New Zealanders Physical Activity and Nutrition 2006. The study found a segment of respondents who were too busy and too stressed to take part in physical activity with any regularity, $67 \%$ were women. This finding invites closer examination of the kinds of barriers that keep women from having opportunities for physical activity: Why is it difficult for women in the 'Busy and Stressed' segment to be able to participate in physical activity?
\end{abstract}

Many studies of physical activity are conducted from a health perspective examined as a population measure assessed in terms of frequency, intensity and duration, and fail to consider the multiple influences that shape women's physical activity decisions. Missing from the literature so far has been a comprehensive look at the factors affecting women's participation in physical activity from the context of their daily lives. This thesis draws on key literature from feminism, leisure studies and psychology and looks specifically at the social and personal context that lies behind women's decision-making about participating in physical activity.

My methodology was based in Feminism and guided by Ecological Theory. Data collected from three focus group discussions centered on personal, social and environmental themes engaged the participants in sharing experiences that influence their opportunities for physical activity. Nineteen women between the ages of 25 and 49 participated in the focus groups. Most of them were in situations where they were juggling partners, work, study, and children and therefore were similar to SPARC's busy and stressed segment, and were not getting the recommended amount of physical activity.

Results show that while the women's attitudes and experiences of physical activity were very positive, and they mainly had good levels of support, there was little time or opportunity to be able to participate in physical activity with any regularity. Women continue to be over represented as inactive in physical activity research, however there is less research at present that includes the voices of women about the trade-offs, uncertainties and negotiations involved in their opportunities to be physically active. This study addresses what I see as a significant gap in the research. 


\section{ACKNOWLEDGEMENTS}

They say the joy is not in arriving but in the journey...I would have to differ here as there is inimitable joy in this accomplishment and hence the arrival. Anyone who knows me will know there have been a few hiccups along the way of the thesis journey.

First, I am especially grateful to all the women who agreed to be involved in my discussion groups, and for contributing to the lively discussions that ensued as a result of coming together. Thank you to Georgia McLaren for her incredible effort and assistance as my note taker.

I would like to thank Sport and Recreation New Zealand (SPARC) for their support via a post-graduate research grant, and a special mention to Dr Maea Hohepa and Grant McLean. I must also thank Jeannette Vine for her help with managing the external grants process, and for her encouragement and inspiration.

I would like to thank my friends for their continued interest and support as I have furthered my academic pursuits over all these years now. I am thankful (nay grateful) for the most wonderful group of colleagues/friends from the SSRE programme and would like to acknowledge Shadiya, Carolyn, Michelle and Anna... 'look at us go girls!' The staff at SACS is highly regarded for their encouragement and practical support always: thank you Carol, Miss Monica, Alison and Adam. Also, particular "thank yous" to A.P. Jenny Neale, for a discerning eye and a friendly ear, and Dr Annette Beasley, always a willing listener. A special thank you must go to my thesis supervisor Dr Lee Davidson - to think this all started with your Leisure Studies paper. Thank you for your expert knowledge and guidance as and when needed.

My final and greatest appreciation goes to my loving family, my husband Jeff Galt and 'the Pearls', Katie and Jemma, for their understanding, help, support and interest in my life outside of them. They have truly been my foundation and encouraged me through some challenging times. 


\section{DEDICATION}

... [she] was reluctant, unready to go out into a world through which she could walk and walk and not ever expect to fall into step with her sister... ${ }^{1}$

In loving memory of my darling sister Duffy, for me but for you too Sugar.

${ }^{1}$ Elizabeth Knox, Billie's Kiss (Wellington: Victoria University Press, 2002). 


\section{CONTENT}

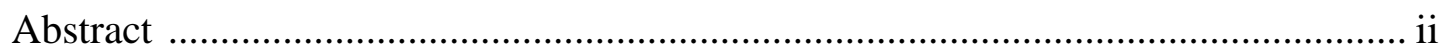

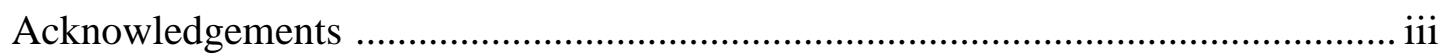

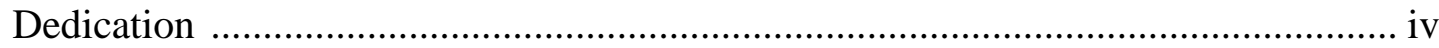

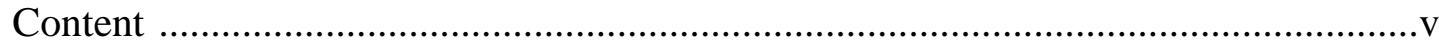

List of Figures and Tables................................................................................... vii

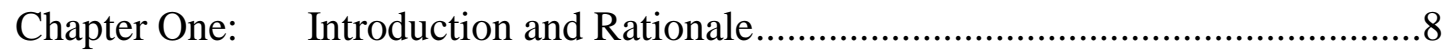

Introduction and Personal experiences ….............................................. 8

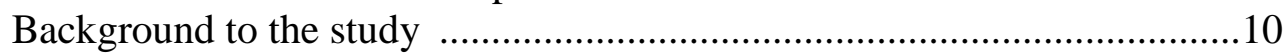

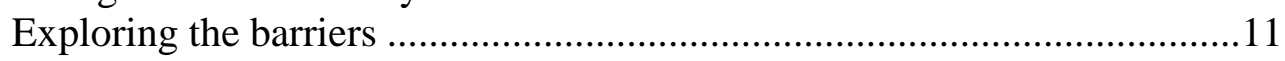

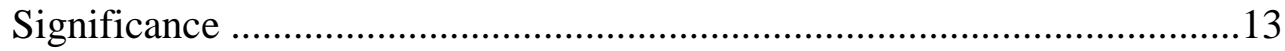

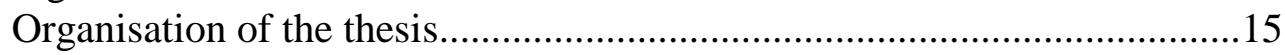

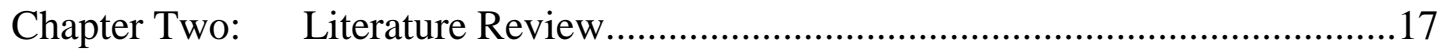

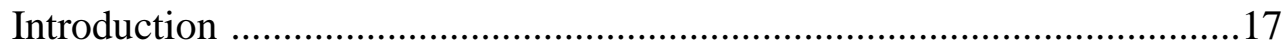

Physical Activity and Health ............................................................18

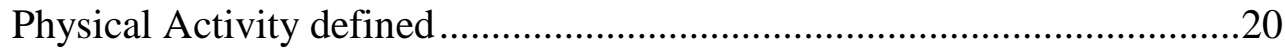

Ecological Theory ...................................................................................23

Women and Physical Activity: exploring the barriers ...............................26

Personal factors that influence Physical Activity ...........................27

Social environment factors that influence Physical Activity ............31

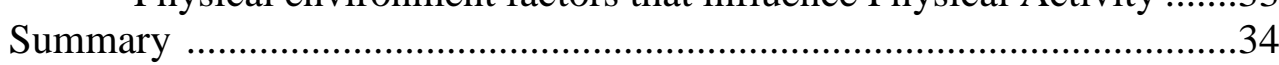

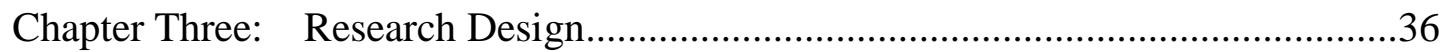

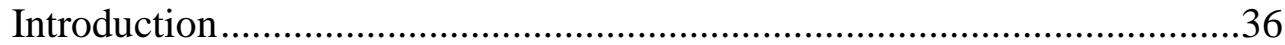

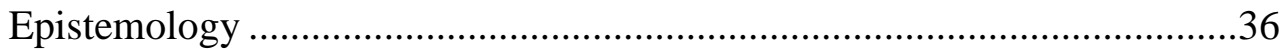

Theoretical Perspective and Methodology...............................................37

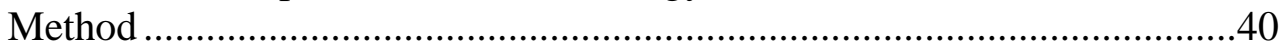

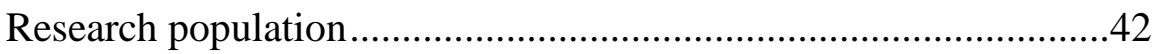

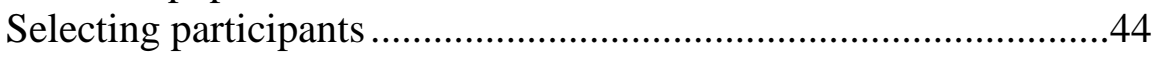

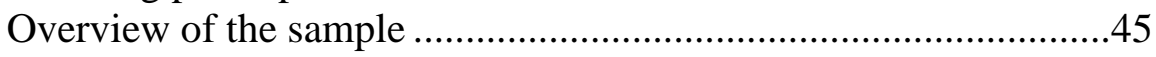

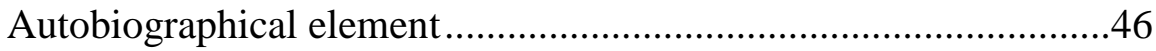

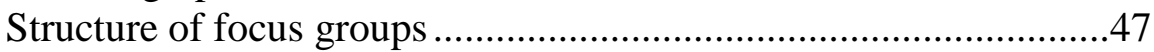

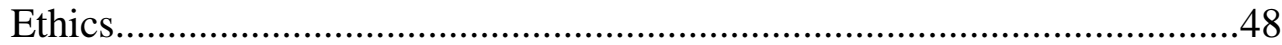

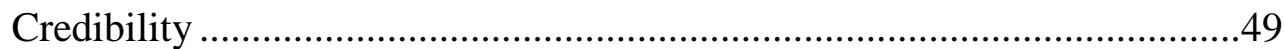

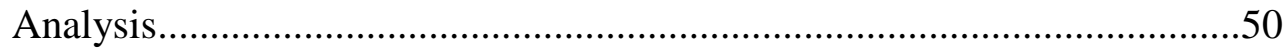

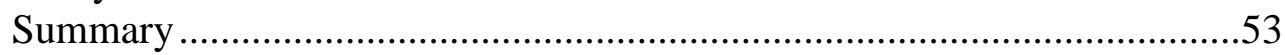

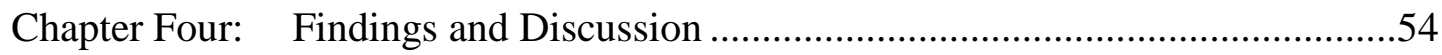

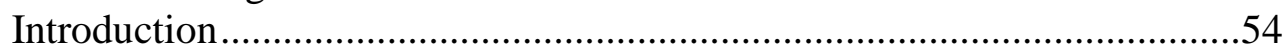

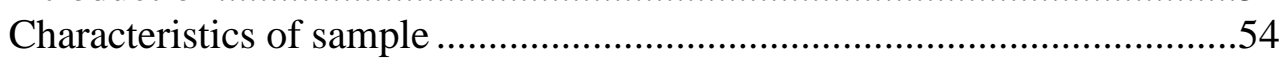

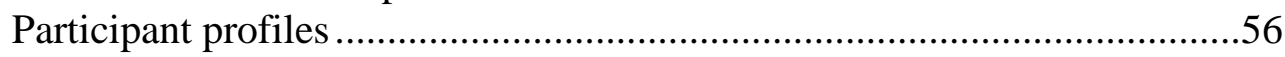

Perceptions of Physical Activity .............................................................59

Personal factors that influence Physical Activity .....................................62 
Social environment factors that influence Physical Activity .....................69

Physical environment factors that influence Physical Activity ...................73

Barriers to opportunities for physical activity ........................................73

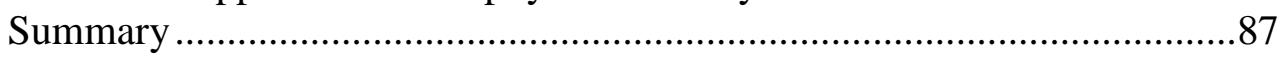

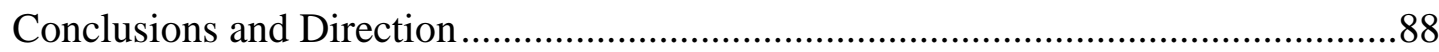

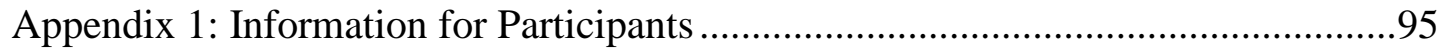

Appendix 2: E-mail letter to Contacts ……….......................................................97

Appendix 3: Follow-up E-mail letter to Group Two participants...............................98

Appendix 4: Focus Group Discussion Guide..............................................................99

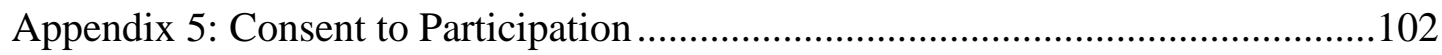

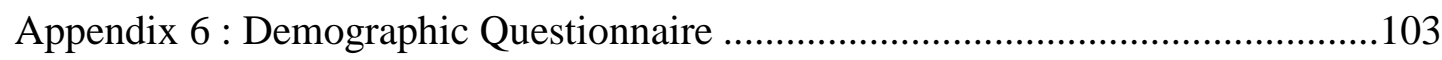

Appendix 7: Researchers Confidentiality Agreement ...........................................105

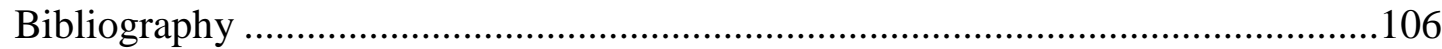




\section{LIST OF FIGURES AND TABLES}

\section{Figures:}

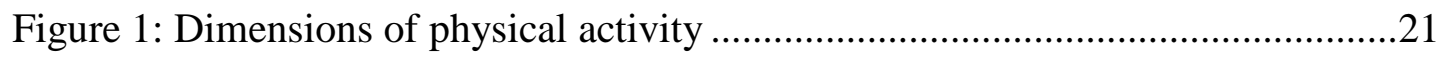

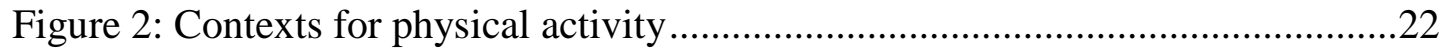

Figure 3: Factors affecting physical activity behaviour..........................................25

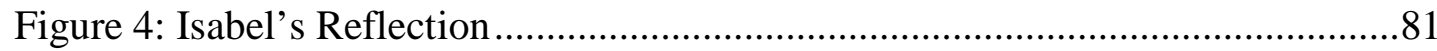

Tables:

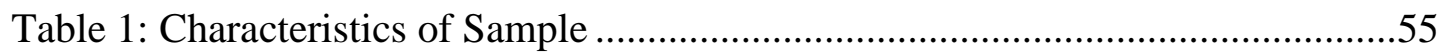




\section{CHAPTER ONE: INTRODUCTION AND RATIONALE}

\section{Introduction and personal experiences}

'So yeah, you do what you can': Exploring the barriers to women's opportunities for physical activity is a study inspired by the findings of the Sport and Recreation New Zealand (SPARC) survey study Obstacles to Action: A study of New Zealanders' Physical Activity and Nutrition (2006). The SPARC study found a segment of respondents who were too busy and too stressed to take part in physical activity with any regularity, $67 \%$, of whom were women. This research was undertaken to further explore the kinds of barriers that women face in finding opportunities for physical activity.

My initial interest in researching women's experiences of opportunities for physical activity stems from my own experience and has an autobiographical element to it. My own experiences come from always having an interest in and participating in physical activity and sport, raising a family and working in paid and unpaid work in some capacity. In and amongst all that, I tried to make sure there was some 'me' time. For me, 'me' time usually means physical activity. Opportunities for free time in the context of working and raising a young family did not always readily present themselves, and sometimes simply getting the opportunity to do some physical activity was a pretty creative process. More often than not, I simply went without, colloquially known as 'burnt chop syndrome'.

I have always been a physical person and continue to be so. As a child, my parents would sometimes want to keep me from participating and competing in sport and physical activity. I was regularly bruised and pushing the injury boundaries, simply because I tried too hard. I do not recall this as being an issue for my older brother. He was able to play hard and was encouraged to do so. There did not appear to be any question about him hurting himself and he was allowed to do all the things I wanted to do too. However, as a girl, I was expected to behave differently from my brother and my identity was polarised between the options of being a 'girlie girl' or a tomboy. I was the youngest of my parents' ten children and next in line to a boy whose 'hand me downs' I received. This did nothing to discourage the 
tomboyishness associated with my physicality. Just as I did not understand why my parents did not want me to be so physically active, neither did they understand why physical activity was important to me.

At various times throughout my life, I have been able to access opportunities for physical activity to varying degrees. This has been difficult at times because of the different roles I have had and what seemed like a constant demand on my time. Between walking the dog, pushing prams or towing trailers on bicycles, physical activity took on an element of utility that I did not recognise as the manner in which I preferred to be physically active. Time constraints and a lack of energy meant opportunities were fragmented, and the options for physical activity were limited. Having come through times fraught with the demands of parenting small children and working or studying part time, and now being active on my own terms again, I have started to reflect on how and why statistically men are more active than women are. Moreover, how is it that women are represented across many populations as being less active than men are? The answer to that may seem self-evident; we have less time, and more to do. However to assume this would be simplistic.

To explain my current situation, I am a forty-something white woman expatriate who came to higher education as a mature student at 33. I was born in Canada to parents with little education (my father was illiterate) outside primary school and come from a blue-collar working class background. I completed high school with an academic matriculation that allowed for university study, though my initial tertiary education was in Fine Arts at a college for art and design. My mother died in my second year at college, an event that would significantly shape the rest of my life. This was when I became involved in cycling and women's groups. I have lived in New Zealand for nearly 20 years, though I can feel, and be made to feel, like an outsider still. My undergraduate degree is in Sociology and Religious Studies and I have a great interest in Feminism.

When it comes to researching, it comes as no surprise that I should want to investigate women and physical activity. I am researching this particular area because I 'fit' my own research question, and I see something of myself in it. I share 
a great deal of common ground on this topic and most likely with the participants. As Morgan states:

...the best match between researchers and participants' interests happen when they share the same goals: producing useful information... ${ }^{2}$

If I were not conducting this research, I would be participating in it. I believe the women who participated in this study want to achieve the same ends as well in producing some useful information to explain why women, in this instance, appear to have fewer opportunities for physical activity.

...I am you - busy, on a budget, overworked, shrewd, cute, clever, finding a way... ${ }^{3}$

I am intrigued by population health statistics and the methods and manner by which this information is gathered, but as a graduate with a degree in sociology, I am more interested in the human social interaction behind those statistics. As a feminist, I have a commitment to women, and want to ask the kinds of underlying questions in regards to physical activity outside of frequency, duration and intensity. Of particular concern are questions to do with equity, support, encouragement and opportunity. These types of questions define a methodology that is substantially different to the current ones used to measure numbers of people involved in physical activity.

\section{Background to the study}

In recent research to gain a snapshot of the country's activity levels, SPARC teamed up with the Cancer Society of New Zealand to produce the Obstacles to Action study (2006). A baseline study on the physical activity and nutritional habits of a sample of the New Zealand population was conducted. The results of this study are presented in a number of reports called 'Obstacles to Action: A Study of New Zealanders' Physical Activity and Nutrition'. From the entire sample $(n=8291)$, the SPARC researcher segmented the respondents into three broad bands: Inactive - those who were inactive and had no intention of becoming active, Active - those who were already active and had been for more than six months, and a remaining Target Group $(n=3700)$ - those who were not regularly active, but who had some intention of becoming active in the

\footnotetext{
${ }^{2}$ David L. Morgan, Successful Focus Groups: Advancing the State of the Art (Newbury Park: Sage, 1993).

${ }^{3}$ Naomi Wolf, "From Lady Di to Michelle Obama," Dominion Post, 5 March 2009.
} 
next six months. The Target Group was then broken down into a further six segments one of which was 'Busy and Stressed'. This segment is the focus of my research question. The most interesting features of the 'Busy and Stressed' are the profile of the segment's makeup. ${ }^{4}$

The demographics of the 'Busy and Stressed' segment are where my real interests lie, as women outnumber men by two to one in this segment. Sixty-one percent of the segment are aged between 25 - 49 and $70 \%$ of the segment are married or living with a partner. The 'Busy and Stressed' segment largely indicated a 'lack of time' and or 'time pressures', as most likely to account for why they did not participate in physical activity. More than half of this group (52\%) work full time and more than half of that again are women (28\%). Fifty-five percent of the segment has children under the age of 18 in the household. ${ }^{5}$

When I read the SPARC report I saw interesting statistics related to a 'lack of time' or 'time pressures', as well as issues of energy and tiredness, as the reasons most likely to account for why the respondents in the 'Busy and Stressed' segment did not participate in physical activity. The high representation of women in this particular segment is intriguing and bears further investigation. This is reiterated in the SPARC report as well, as it is noted that:

....A qualitative research phase could be particularly important to improve understanding of the aspects of their lives that underpin the perceived lack of time and high levels of stress that affect the Busy and Stressed segment (p17). ${ }^{6}$

\section{Exploring the barriers}

The over-representation of women in the 'busy and stressed' segment raises a number of discussion themes around several general areas. For example, why in the research are women generally less active than men? It is interesting to conceive of how

\footnotetext{
${ }^{4}$ Charles Sullivan et al., "Obstacles to Action: A Study of New Zealanders' Physical Activity and Nutrition Overview Report," in Obstacles to Action: A Study of New Zealanders' Physical Activity and Nutrition, ed. A.C. Neilsen (Wellington: 2003), Charles Sullivan et al., "Obstacles to Action: A Study of New Zealanders' Physical Activity and Nutrition Profiling Busy and Stressed," (2006).

${ }^{5}$ Sullivan et al., "Obstacles to Action: A Study of New Zealanders' Physical Activity and Nutrition Profiling Busy and Stressed."

${ }^{6}$ Ibid.
} 
women may react to this statistic. There may be a concern that this type of statistic may not stimulate women to make more attempts to be physically active, and may even result in fewer attempts to be physically active. Undoubtedly, the opposite of physical activity is physical inactivity, and although according to the statistics women are less physically active than men are, it is unlikely they could be deemed physically inactive. The quantitative aspects behind this research statistic, though useful, can only tell a portion of the story, and not the bit that I find the most interesting or useful for me. If existing literature does not explain my research problem, or if a current approach to that problem is not working, then that suggests to me I need to look at my problem in a different way. ${ }^{7}$

Is there a relationship between the over-representation of women in the 'Busy and Stressed' segment, and the lack of opportunities for physical activity based on time constraints? And if there is, what lies behind that relationship? Is it more difficult for women to have opportunities to participate in physical activity because of constraints that may be more restrictive for women, and what they have to do, or with their particular commitments? Accordingly, my research question is aimed at exploring the barriers to women's participation in physical activity:

Why is it difficult for women in the 'Busy and Stressed' segment to be able to participate in physical activity?

My research paradigm is based in social constructionism. My position is that knowledge is a product of humans' interactions with each other and the material world. Interaction is by definition social, and any form of reality is based in the social world and, depending on what you want to learn, is subjective. What you see depends on whose perspective you take. Social constructionists examine social life through specific lenses, and my lens is based in feminism (with critical ideals), and as such, I take a few points as being central to my inquiry. I begin from a position of an issue that has to do with women. I explicitly seek to answer my research question in a manner that bears the hallmarks of the women who participated in my study; that is

${ }^{7}$ Stuart H. Biddle and Nanette Mutrie, Psychology of Physical Activity Determinants, Well-Being and Interventions, 2nd ed. (Abingdon: Routledge, 2008). 
in their words, their voices, and the importance of the events in their worlds. ${ }^{8}$ Lastly, I work under the premise that we are all as equal in the research process as we can be given that ultimately participants are the holders of the knowledge that I am seeking.

A further framework for the study was provided by adopting an ecological perspective. An ecological perspective encompasses context in the manner that extends to include the physical, social, cultural and historical aspects of the environment and takes into consideration the attributes and behaviours of the persons within that environment. Major themes in ecological theory emphasise interconnectedness and mutual interaction among people and settings as well as an emphasis on studying behaviour in natural circumstances. The idea here is to understand behaviour in context; however, context needs to be understood in terms of how different people experience it. ${ }^{9}$

My main aim was to explore why it is difficult for women in the 'Busy and Stressed' segment to be able to participate in physical activity, and in doing so, I undertook the following objectives:

- To explore the social environment factors that support, constrain and influence opportunities for physical activity, for example family, and paid and unpaid work commitments.

- To investigate motivation, intrinsic and extrinsic, and personal factors like attitudes, meaning and perceived benefits of physical activity.

- To consider current behaviour and patterns of physical activity, how this changes and in what context. ${ }^{10}$

\section{Significance}

Previous research in New Zealand has paid little specific attention to women's experiences with physical activity. Much of the research comes from a health

\footnotetext{
${ }^{8}$ Jenny Kitzinger, "Qualitative Research: Introducing Focus Groups," British Medical Journal 311, no. 7000 (1995).

${ }^{9}$ Lindsay Mclaren and Penelope Hawe, "Ecological Perspectives in Health Research," Journal of Epidemiology and Community Health 59 (2005).

${ }^{10}$ Grant McLean and Marinka Teague, "Obstacles to Action: A Study of New Zealanders Physical Activity and Nutrition," in Social Policy and Research and Evaluation Conference (Wellington, New Zealand: 2004).
} 
perspective and is based on health promotion, and fails to address the significance of the complexity of social life when it comes to the everyday lived experiences of women. There is also not much in the way of a socio-cultural account of physical activity as an expression of enjoyment. When considering the lack of knowledge about women's specific physical activity (health, sport and or otherwise) the significance of my research lies in the contribution to knowledge development in an underdeveloped research area.

The fact that there is a paucity of research undertaken with women and physical activity in New Zealand does not imply that the topic is not important. We already know plenty about physical activity, but not in a form, that serves women best, and we need to know much more. Women are positioned in population physical activity research as predominantly 'inactive' or 'insufficiently active'. If the goal is to get women to increase their physical activity levels, then exploring and identifying the variables that help explain the reasons for their inactivity is appropriate. Research conducted qualitatively can provide the insights surrounding women's physical activity opportunities and decisions.

While previous research may outline differences in men's access, attitudes and experience and women's access, attitudes and experience of physical activity, this is only a beginning. It is the reasons for these differences that need to be explored. ${ }^{11}$ Research on women and physical activity specifically needs to address women's experiences of everyday life and the attempts to negotiate opportunities for physical activity in that context. For example, prior research indicates that women and men have different patterns of physical activity. ${ }^{12}$ Participating in or maintaining regular physical activity for women is a complex behaviour involving multiple relationships and influences, and needs to be explained and described as such.

Current research on physical activity, as it is often framed, considers the issue of physical activity within a health discourse. Whilst health outcomes are important,

\footnotetext{
${ }^{11}$ Karla A. Henderson et al., Both Gains and Gaps: Feminist Perspectives on Women's Leisure (State College: Venture Publishing Inc, 1996).

${ }^{12}$ Philayrath Phongsavan, McLean Grant, and Adrian Bauman, "Gender Differences in Influences of Perceived Environmental and Psychosocial Correlates on Recommended Level of Physical Activity among New Zealanders," Psychology of Sport and Exercise 8, no. 6 (2007).
} 
research has shown that they are not enough of a motivator on its own to change physical activity behaviour. ${ }^{13}$ Inactivity that is presented as risk, may be no real risk at all, and there are many for whom non-participation in physical activity does not hold any real risk. While health risks associated with inactivity are also important, a model in favour of arguing for physical activity can be considered outside the health perspective (though that activity may still have the benefits of a health outcome). This study considers physical activity from another perspective and pays close attention to context and everyday living.

Feminist research provides a different and distinct way of looking at the world. I am interested in providing a feminist account of women's participation in physical activity; what kind of activities they participate in, and how and when they get to do so. There is a gap in research on context when it comes to physical activity on New Zealand women. Women's experiences with everyday life and living affect women's choices to be physically active or not. In order to address the inequality in women's physical activity participation and explain why they have fewer opportunities, there is an important need for research with that focus. New Zealand physical activity literature needs a way of looking at physical activity (outside of health), and understanding physical activity behaviour as it is situated in the lives of women (in routines and practices, and schedules).

\section{Organisation of the Thesis}

This thesis consists of four chapters and a conclusion. Beginning with this introduction, I explain my interest in the topic, and how I came to be involved in research with women and physical activity. Chapter One also presents the research problem and an outline of the study.

Chapter Two provides a background to the research and a review of the literature. The research is situated in the context of the findings of other research conducted in New Zealand providing some interesting statistics, and is a useful place to start. The literature review examines studies, mainly journal articles, based in health and leisure

\footnotetext{
${ }^{13}$ Sullivan et al., "Obstacles to Action: A Study of New Zealanders' Physical Activity and Nutrition Profiling Busy and Stressed."
} 
studies that explore physical activity from an ecological and or feminist perspective. While most of the literature is from a health-related perspective, there are some studies on physical activity that fall outside the health paradigm. Mostly these are written from a feminist perspective in the leisure studies literature, but there are also good examples in the literature from other disciplines such as gender studies, women's studies, and psychology. In using other disciplines, I am attempting to gain an understanding of the socio-cultural aspects of physical activity. The majority of the literature is drawn from overseas examples, the United States, Canada, Australia and the United Kingdom. However, a small amount is from New Zealand sources.

In Chapter Three, I present my methodological approach and research design, and provide a rationale for why I chose to approach the study in this manner. I also explain my chosen method - focus groups, and analysis - thematic analysis as well as ethical implications and consideration, and the credibility of the research.

In Chapter Four, I present the characteristics of the sample, and provide a small profile of each of the women who participated in the focus group discussions. The findings and analysis of the focus groups' discussions are presented as well, and are interspersed with quotations from the women's conversations. This chapter illustrates the challenges the women face in managing multiple social roles as partners, parents, caregivers and workers.

Finally, I present my conclusions and outline some direction for further study with women and physical activity, and discuss the limitations of the study. 


\section{CHAPTER TWO: LITERATURE REVIEW}

\section{Introduction}

This chapter discusses the relationship between physical activity and health, and how this has become such a pressing issue internationally. It also includes coverage of what is meant by physical activity, how this is articulated, and what is currently known about how women experience physical activity.

In my search for literature on this topic, I looked primarily at information from the past two decades, although earlier publications have been included where they have ongoing relevance, and particularly where they fill a gap that exists later in the time frame. The aim of this approach was to ensure a focus on recent findings, initiatives or evaluations. I was most interested in studies that were similar to what I wanted to do, specifically qualitative studies with a focus on women and those that were based in feminism and ecological theory. As few such studies exist within the New Zealand context, most of the literature reviewed comes from international sources, including the United States, Canada, the United Kingdom and Australia.

I have excluded solely health-based studies from my discussion, though much of the physical activity literature uses the health benefits outcomes and health models as a place to start. Instead, I have focused on literature that deals with the social aspects of physical activity such as enjoyment, and physicality, and leisure time physical activity. This was used as a basis for the way I wanted to explore physical activity and opportunities for it.

In the discussion that follows, I have used a framework based on ecological theory to examine a range of barriers identified as limiting women's opportunities for physical activity. Within the ecological model, barriers are explored using the concentric zones theory, which emphasises interconnectedness between various factors. The ecological environment is conceived of as extending far beyond the immediate situation of the individual, and the evidence points to a complexity of daily life that makes it difficult for women to fit physical activity into their day. 
This complexity includes social environment factors like family and paid or unpaid work commitments; motivational and personal factors, and patterns of physical activity for women across life stages and during life cycles ${ }^{14}$. Before I address the literature on these themes, however, I will briefly comment on the relationship between health and physical activity and the paradigm shift in health during the last 30 years.

\section{Physical activity and health}

The health benefits from physical activity have been established for some time now and are well canvassed in the literature. Physical activity as a health benefit has its history in the effects of a sedentary lifestyle following the physicality associated with life before the Industrial Age. Physical activity based in primary health care was established in the Declaration of Alma-Ata, 1978. Alma-Ata was the first international conference on primary health care and was organised by the World Health Organisation (WHO) and United Nations Children's Fund (UNICEF) and is seen as a major milestone in public health. As was established at Alma-Ata, and stated in the Declaration, the focus of primary health care was to be the attainment of 'Health for All'. By extension, the Ottawa Charter (1986) puts the attainment of this goal into action with an emphasis on health promotion. Health promotion is the process of enabling people to increase control over, and to improve their health, and this has led to a re-orientation of health services to be more encompassing.

The publication of the US Surgeon General's report on physical activity and health (US Department of Health and Human Services 1996) was the most pivotal piece of research highlighting the relationship between physical activity and population health. The report identified that physical activity can reduce the risk, and modify the effects, of many major non-communicable diseases and conditions like cardiovascular diseases, cancer, diabetes, osteoporosis, obesity and depression. The report is responsible for recommending that adults should undertake at least 30 minutes of moderate-intensity physical activity on most,

\footnotetext{
${ }^{14}$ Phongsavan, McLean Grant, and Bauman, "Gender Differences in Influences of Perceived Environmental and Psychosocial Correlates on Recommended Level of Physical Activity among New Zealanders.", Allender Steven, Cowburn Gill, and Foster Charlie, "Understanding Participation in Sport and Physical Activity among Children and Adults: A Review of Qualitative Studies," Health Education Research 21, no. 6 (2006).
} 
if not all, days of the week. ${ }^{15}$ Many countries, including New Zealand, have implemented health promotion programmes ${ }^{16}$ to increase the physical activity levels of their populations based on this evidence.

SPARC is responsible for monitoring and promoting physical activity and sport in New Zealand. SPARC is a Crown Agency, formed in 2002, and is an amalgamation of three main organizations that were previously responsible for promoting and supporting sport and recreation in New Zealand: The Hillary Commission, the policy arm of The Office of Tourism and Sport, and the New Zealand Sports Foundation. A Crown Agency is a type of Crown Entity that is established by or under an Act. In the case of SPARC, this is the Sport and Recreation Act 2002. Crown Entities are legally separate from the Crown and operate at arms length from the responsible or shareholding Minister. However, a Crown Entity must give effect to government policy when directed by the responsible Minister. ${ }^{17}$

\footnotetext{
${ }^{15}$ CDC Centers for Disease Control and Prevention, "Physical Activity and Health: A Report of the Surgeon General," ed. Division of Nutrition and Physical Activity (1999).

${ }^{16}$ Phillip B. Sparling et al., "Promoting Physical Activity: The New Imperative for Public Health," Health Education Research 15, no. 3 (2000).

${ }^{17}$ State Services Commission, "Crown Entities," http://www.ssc.govt.nz/display/home.asp.
} 


\section{Physical activity defined}

There are a variety of definitions of physical activity, but the ones that are widely accepted by physical activity researchers are given by Carl Caspersen and the World Health Organisation (WHO). According to Caspersen et al. (1985):

Physical activity is defined as any bodily movement produced by skeletal muscles that results in energy expenditure....physical activity in daily life can be categorised into occupational, sports, conditioning, household or other activities.

Exercise is a subset of physical activity that is planned, structured, and repetitive and has as a final or an intermediate objective the improvement or maintenance of physical fitness. ${ }^{18}$

According to the World Health Organisation:

Physical activity is defined as any bodily movement produced by skeletal muscles that require energy expenditure. ${ }^{19}$

In physical activity research, a number of indicators to do with mode, frequency, duration, intensity and the context in which it is undertaken is used to measure physical activity. Mode is the type of activity undertaken, frequency refers to how often someone does physical activity, duration is for how long, intensity has to do with exertion (light, moderate, vigorous), and context refers to the purpose for which the physical activity is being engaged in (see Figure 1 below). There is also reference to 'Regular Physical Activity' which means at least 15 minutes of vigorous activity makes you huff and puff - or a total of 30 minutes or more of moderate activity causes a slight but noticeable increase in breathing and heart rate - each day for 5 or more days each week. ${ }^{20}$

\footnotetext{
${ }^{18}$ C. J. Caspersen, K. E. Powell, and G. M. Christenson, "Physical Activity, Exercise, and Physical Fitness: Definitions and Distinctions for Health Related Research," (Public Health Reports 100, 1985). ${ }^{19}$ WHO World Health Organisation, "Physical Activity," http://www.who.int/topics/physical_activity/en/.

${ }^{20}$ SPARC Sport and Recreation New Zealand, "Changing Physical Activity Behaviour: Key Lessons Learned from Regional and District Physical Activity Strategies," http://www.sparc.org.nz/filedownload?id=8c988113-02cd-4fc7-a59a-f36d6316e6ec.
} 
Figure 1: Dimensions of physical activity

\section{Physical activity has five dimensions:}

\begin{tabular}{|c|c|}
\hline $\begin{array}{c}\text { PHYSICAL } \\
\text { ACTIVITY }\end{array}$ & \multicolumn{2}{|c|}{} \\
\hline CONTEXT & The descriptive category of physical activity \\
\hline TYPE & $\begin{array}{r}\text { The kind (mode) of physical activity - for example, } \\
\text { aerobic activity or resistance activity }\end{array}$ \\
\hline FREQUENCY & How often a person is physically active i.e. daily \\
\hline INTENSITY & The level of exertion - light, moderate, vigorous \\
\hline DURATION & How long the activity lasts e.g. 30 minutes \\
\hline
\end{tabular}

Source: Changing Physical Activity Behaviour - SPARC (2005)

Contexts for physical activity are typically referred to as 'domains' and can be identified under various categories. For example: leisure-time physical activity (this includes sport and recreation), occupational physical activity or physical activity that takes place as work, active transportation like cycling or walking as a means of (usually) getting to work or other places, and incidental and household, and other physical activity which encompasses activities like housework, gardening, family or child care. Categories like physical education, exercise and fitness as well as game playing or play could also be included. "Incidental and household", and other physical activity is sometimes associated with the concept of "utility" in physical activity. This is when physical activity is undertaken for a specific purpose and with an anticipated outcome or result. For example, washing the car may be categorised as incidental physical activity, where washing the car is done to complete a chosen task rather than undertaking physical activity. (See Figure 2 below) 
Figure 2: Contexts for physical activity

\section{Physical activity contexts}

\begin{tabular}{|c|c|}
\hline CONTEXT & \\
\hline $\begin{array}{l}\text { Sport -social, } \\
\text { competitive }\end{array}$ & $\begin{array}{l}\text { Institutionalised, competitive activity requiring the use of relatively } \\
\text { complex physical skills }\end{array}$ \\
\hline $\begin{array}{l}\text { Physical } \\
\text { Recreation }\end{array}$ & $\begin{array}{l}\text { Activity requiring physical exertion and sometimes physical skill, } \\
\text { which by its nature is participative and enjoyment/fun oriented. }\end{array}$ \\
\hline $\begin{array}{l}\text { Physical } \\
\text { Education }\end{array}$ & $\begin{array}{c}\text { Learning in, through and about movement that is delivered in the } \\
\text { school environment to provide skills, attitudes, values, knowledge and } \\
\text { understanding for life-long participation. }\end{array}$ \\
\hline $\begin{array}{l}\text { Active } \\
\text { transport }\end{array}$ & $\begin{array}{l}\text { Using physically active forms of transport to move from place to place } \\
\text { such as walking, running and cycling }\end{array}$ \\
\hline Exercise & $\begin{array}{l}\text { Specific types of physical activity done to improve or maintain } \\
\text { physical fitness and health. Can be vigorous or moderate intensity. }\end{array}$ \\
\hline $\begin{array}{l}\text { Fitness } \\
\text { activities }\end{array}$ & $\begin{array}{c}\text { Activity motivated by the desire to improve the physiological } \\
\text { performance of an individual either as an end in itself of for a specific } \\
\text { purpose }\end{array}$ \\
\hline Play & $\begin{array}{l}\text { Activity engaged in by children that is guided more by imagination } \\
\text { than by fixed rules }\end{array}$ \\
\hline $\begin{array}{l}\text { Deliberate } \\
\text { play }\end{array}$ & $\begin{array}{l}\text { Structured activity that requires the development of particular } \\
\text { techniques and tactical understanding. }\end{array}$ \\
\hline
\end{tabular}

\section{NB: This is not an exhaustive list.}

Source: Changing Physical Activity Behaviour - SPARC (2005)

The terms 'sport', 'physical recreation', 'exercise', and 'physical activity' often overlap or are used interchangeably, while at other times they may have very specific meanings depending on the context. This has the potential to cause confusion or miscommunication of ideas and has led to a provisional definition of physical activity from SPARC as:

'movement required on a daily basis to sustain health'. Physical activity opportunities include sport, active recreation, physical education, fitness activities, active transport and play'. ${ }^{21}$ 
For the purposes of this research, when the term physical activity is used it is in reference generally to any form of physical activity, as any of the above terms will be encompassed under a global usage of the term. New Zealand, through SPARC and the Ministry of Health $(\mathrm{MoH})$, has adopted National Physical Activity Guidelines, which state that adults should participate in at least 30 minutes of moderate-intensity physical activity on most, if not on all days of the week. Moderate intensity physical activity is described as physical activity that will cause a slight, but noticeable, increase in breathing and heart rate. ${ }^{22}$

\section{Ecological Theory}

I employed an ecological model to explore extenuating factors that are likely to affect women's opportunities for physical activity. The foundation question addressed in ecology theory is the relationship between human behaviour and the environment ${ }^{23}$ and is based on a systems model of behaviour. An ecological model recognises individual behaviour and also focuses on environmental factors that may contribute to individual behaviours and consequently actions - in other words context. Ecological theory in sociology stems from the University of Chicago in the 1920s where it was developed most widely to explain urban social change. Borrowing from plant ecology, Ernest Burgess developed an urban ecology, which pictured the environment of the city as a series of social forces competing for scarce urban resources. He illustrated this concept as a series of concentric rings that expand radially from a central core. $^{24}$ This model, known as the concentric zone model, has been adapted and applied creatively in many other 'applications'.

From a health perspective, the ecological model is adapted from psychology and Uri Bronfenbrenner's (adapted from Lewin) conceptualisation of the concentric rings model as applied to child development and behaviour. Bronfenbrenner uses an ecological model of behaviour and concentric zones theory to illustrate the possible sources of influence in a child's life, presented as a set of "nested" environments.

\footnotetext{
22 _

${ }^{23}$ Michael Q. Patton, Qualitative Research and Evaluation Methods, 3rd ed. (Thousand Oaks: Sage Publications Inc., 2002).

${ }^{24}$ Robert E. Park, Ernest W. Burgess, and Roderick D. McKenzie, The City (Chicago: The University of Chicago Press, 1925).
} 
Bronfenbrenner's structure of concentric rings begin with the individual at the 'core' and works outward to include a respective number of environmental systems said to have influence on child development. The first system outside the individual is the 'microsystem', and includes immediate social groups and settings like the family and the home. The 'mesosystem' goes further abroad with the inclusion of groups and social institutions such as schools or the workplace, while the 'exosystem' contains another level of relationships, like neighbourhoods or community where the individual may not be directly involved in that system though they may still experience influences from that system. The 'macrosystem' expands to include social institutions common to a particular culture. Each environment has an influence on the individual (though this may be not directly) which produces a rippling effect whereby any activity from one environment ripples into surrounding environments. This is the principle of interconnectedness, and applies not only within settings, but also with equal influence between settings. Therefore, nothing is considered in isolation and the ecological environment is conceived of as extending far beyond the immediate situation of the individual. ${ }^{25}$

Ecological models of behaviour have come to be widely used in research and over the years have been adapted and evolved into a model that can specifically be applied to physical activity research. Ecological models used in attempting to understand health behaviours are applied to physical activity in this context as well. (See Figure 3 below) "Environment" pertains to 'anything outside' the individual. The physical environment is a central feature of the ecological model and is included here. An ecological model recognizes that multiple facets of the physical and social environment influence individuals and that human environments are multidimensional and complex, and above all, are the context for human action. ${ }^{26}$ This perspective is grounded in the concept of interrelations between environmental conditions and human actions. ${ }^{27}$ The model is useful in aiding and understanding physical activity opportunities for women, because it recognises that potential constraints come from many influences, e.g. individual, societal, and organisational,

\footnotetext{
${ }^{25}$ Uri Bronfenbrenner, Making Human Beings Human: Bioecological Perspectives on Human Development (Thousand Oaks: Sage Publications Inc, 2005).

${ }^{26}$ Patton, Qualitative Research and Evaluation Methods.

${ }^{27}$ Mary McElroy, Resistance to Exercise: A Social Analysis of Inactivity, ed. Human Kinetics (Champaign: Kansas State University, 2002).
} 
and that various externalities placed on women may limit their opportunities for physical activity. In using an ecological model, I employ a model that recognises the many layers that potentially influence physical activity behaviour. ${ }^{28}$

Figure 3: Factors affecting physical activity behaviour

\section{Factors affecting physical activity behaviour}
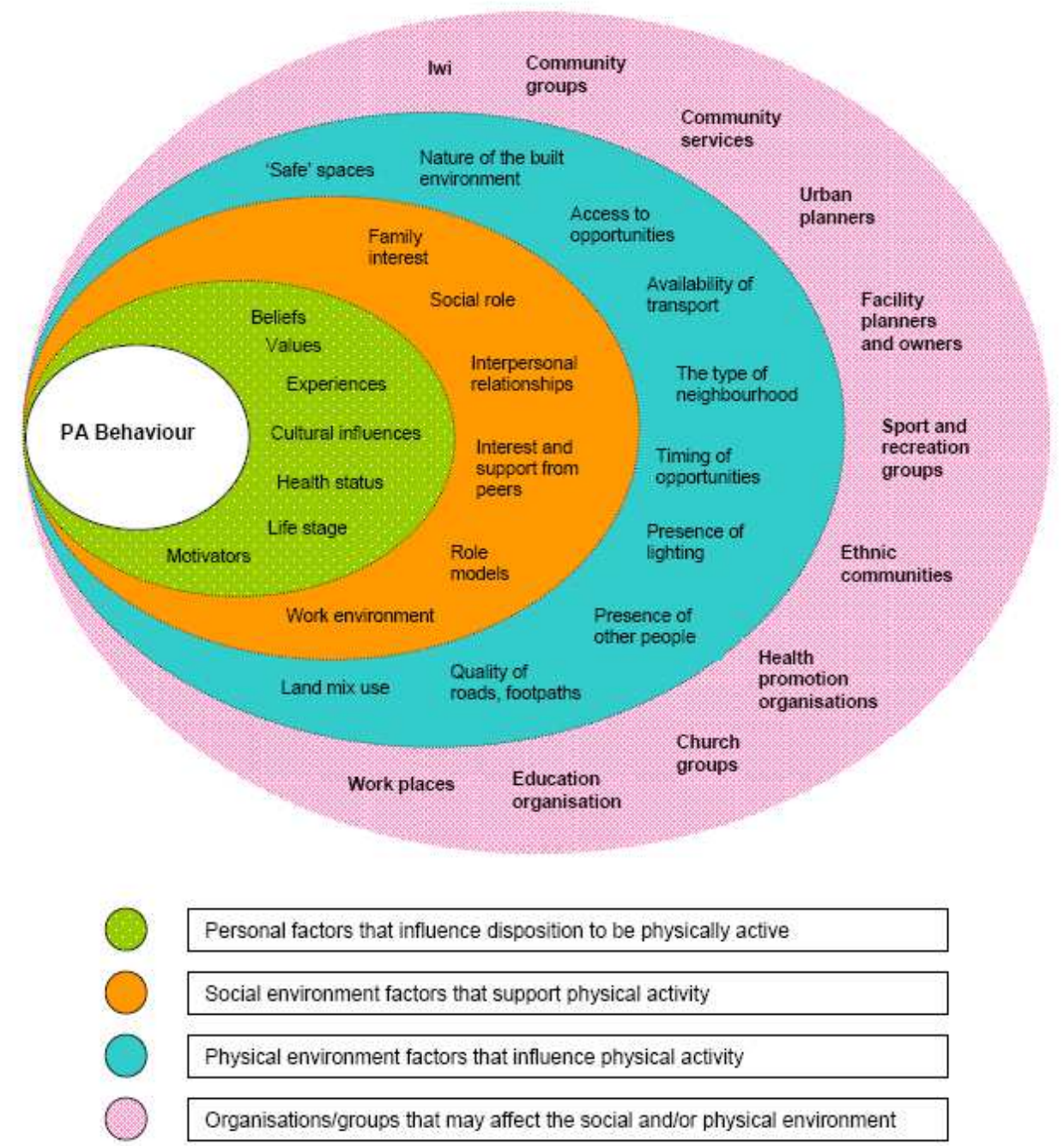

Source: Changing Physical Activity Behaviour - SPARC (2005)

Perhaps the most beneficial theme in an ecological approach is the idea that there are several levels of influence on behaviour i.e. personal, social environment, physical environment and community and social structure. The levels of influence are extended to include multiple settings (school, work, community). ${ }^{29}$ The literature

\footnotetext{
${ }^{28}$ Amy E. Eyler et al., "Correlates of Physical Activity among Women from Diverse Racial/Ethnic Groups," Journal of Women's Health \& Gender-Based Medicine 11, no. 3 (2002).

${ }^{29}$ Centers for Disease Control and Prevention, "Physical Activity and Health: A Report of the Surgeon General."
} 
supports the ecological model and provides ample information on the identifying features of this model, and acknowledges the interconnectedness of each of the features as potential enablers as well as constraints.

\section{Women and physical activity: exploring the barriers}

In terms of active populations today, women are less likely to be as physically active as men. ${ }^{30}$ This is nothing new and has historically been the case with women and physical activity. ${ }^{31}$ While the health benefits of physical activity are widely known, many researchers have found that activity levels for women internationally still remain low. ${ }^{32}$ The reasons for this, in part, appear to be situated around a number of identifiable barriers to physical activity specific to women. ${ }^{33}$

Barriers facing women in physical activity, in an ecological model, are explored over several environments, mainly: personal factors, social environmental and more recently physical environmental factors. Personal factors have to do with issues like past experiences with physical activity and the belief whether one can do, or participate in physical activity, enjoyment of physical activity, health status, and life stage. Social factors could include support, or lack of, from family and friends, and one's social role in the family, whether one works in paid employment, and how much time is spent doing so. Environmental factors have to do with not only the social environment, but the nature of the physical and built environment as well. Studies have shown the significance of opportunities for physical activity based around access to, and characteristics of, the physical and built environment. ${ }^{34}$ There is an increased interest in physical activity using this kind of ecological approach, as

\footnotetext{
${ }^{30}$ Ibid.

${ }^{31}$ Karla A. Henderson and M. Deborah Bialeschki, "Inclusive Physical Activity Programming for Girls and Women," Parks and Recreation 30, no. 3 (1995).

${ }^{32}$ AWRA Australian Womensport and Recreation Association, "About Time: Women in Sport and Recreation in Australia."

${ }^{33}$ Michelle Segar et al., "Fitting Fitness into Women's Lives: Effects of a Gender-Tailored Physical Activity Intervention," Women's Health Issues 12, no. 6 (2002), L. S. Tavares and R. C. Plotnikoff, "Not Enough Time? Individual and Environmental Implications for Workplace Physical Activity Programming among Women with and without Young Children," Health Care for Women International 29, no. 3 (2008).

${ }^{34}$ James F. Sallis, Adrian Bauman, and Michael Pratt, "Environmental and Policy Interventions to Promote Physical Activity," American Journal of Preventive Medicine 15, no. 4 (1998).
} 
it affords an emphasis to the physical environment as well as to social and personal factors in helping facilitate opportunities for physical activity.

Much of the research gathered alludes to specific barriers, explored along an ecological triad, that apply to women outside of the usual issues to do with simply not having enough time. ${ }^{35}$ These types of barriers are much more difficult to overcome and are not always of a kind that can be addressed by raising awareness. ${ }^{36}$ The overseas examples provide confirmation of the complexity of the factors contributing to the lack of opportunities for women to participate in physical activity. ${ }^{37} \mathrm{In}$ exploring the interrelationships of work-family roles and free-time experience, the idea of whether marriage, children and employment curtail women's free time (as well as the role that gender plays) is considered. ${ }^{38}$ Again, many studies from a wide range of disciplines show that time (or lack of it) is a key inhibitor of women's participation in physical activity. Paid work is considered to be one of the greatest usurpers of women's time, as women who work continue to balance family responsibilities that are still largely assumed women's work. ${ }^{39}$

\section{Personal factors that influence physical activity}

Exploring personal factors has to do with investigating behaviours associated with motivations, attitudes and beliefs to do with physical activity. ${ }^{40}$ Examples include the

\footnotetext{
${ }^{35}$ Segar et al., "Fitting Fitness into Women's Lives: Effects of a Gender-Tailored Physical Activity Intervention." Tavares and Plotnikoff, "Not Enough Time? Individual and Environmental Implications for Workplace Physical Activity Programming among Women with and without Young Children." ${ }^{36}$ McLean and Teague, "Obstacles to Action: A Study of New Zealanders Physical Activity and Nutrition."

${ }^{37}$ Kylie Ball, "People, Places ... And Other People? Integrating Understanding of Intrapersonal, Social and Environmental Determinants of Physical Activity," Journal of Science and Medicine in Sport 9, no. 5 (2006).

${ }^{38}$ Kai H. Bellows-Riecken and Ryan E. Rhodes, "A Birth of Inactivity? A Review of Physical Activity and Parenthood," Preventive Medicine 46, no. 2 (2008). Eun-Ok Im et al., "Midlife Women's Attitudes toward Physical Activity," Journal of Obstetric, Gynecologic, \& Neonatal Nursing 37, no. 2 (2008). Segar et al., "Fitting Fitness into Women's Lives: Effects of a Gender-Tailored Physical Activity Intervention."

${ }^{39}$ Tavares and Plotnikoff, "Not Enough Time? Individual and Environmental Implications for Workplace Physical Activity Programming among Women with and without Young Children." M. J. Verhoef, E. J. Love, and M. S. Rose, "Women's Social Roles and Their Exercise Participation," Women and Health 19, no. 4 (1992). Paul Callister, "The Changing Gender Distribution of Paid and Unpaid Work in New Zealand," (Wellington: 2005).

${ }^{40}$ Im et al., "Midlife Women's Attitudes toward Physical Activity.", Karla A. Henderson, "Women, Physical Activity, and Leisure: Jeopardy or Wheel of Fortune?," Women in Sport \& Physical Activity Journal 12, no. 1 (2003b).
} 
benefits, physical and emotional ${ }^{41}$, enjoyment ${ }^{42}$, self-efficacy ${ }^{43}$ and understanding of the role of physical activity in women's lives. Included are the concepts of understanding current approaches to, and strategies for, being physically active and attitudes to self-care prioritisation and taking time out. ${ }^{44}$ Here the concept of self-care is regarded independent of health per se, but reflects a caring for the self with regards to making time for self. Research shows that while awareness of the importance of physical activity is high, participation rates remain low. ${ }^{45}$ Indeed, women from the group that my demographic is based on, that work and tend to have children in the household do acknowledge and understand the health and non-health benefits of physical activity. However, the disconnection appears to be that knowledge alone is insufficient to make physical activity a priority. ${ }^{46}$ This is well illustrated in the literature, as just knowing about the benefits of a behaviour does not necessarily eventuate in raised levels of physical activity amongst women. ${ }^{47}$

Motivation, both intrinsic and extrinsic, to participate in physical activity is key. Intrinsic motivations include doing or participating in an activity for the enjoyment or pleasure of the activity itself. That is, the activities provide their own rewards such as relaxation, enjoyment and satisfaction. Intrinsic motivation can also include beliefs about the activity such as participating in an activity because the activity is good for you and it is the right thing to do. Extrinsic motivation influences one to do things for 'tangible rewards' or social pressures, rather than for the fun of it. This is motivation

\footnotetext{
${ }^{41}$ Marie Dacey, Amy Baltzell, and Len Zaichkowsky, "Factors in Women's Maintenance of Vigorous or Moderate Physical Activity," Women in Sport \& Physical Activity Journal 12, no. 1 (2003).

Henderson, "Women, Physical Activity, and Leisure: Jeopardy or Wheel of Fortune?." M. Segar et al., "Midlife Women's Physical Activity Goals: Sociocultural Influences and Effects on Behavioral Regulation," Sex Roles 57 (2007).

${ }^{42}$ Henderson, "Women, Physical Activity, and Leisure: Jeopardy or Wheel of Fortune?." Kylie Ball et al., "Personal, Social and Environmental Determinants of Educational Inequalities in Walking: A Multilevel Study," Journal of Epidemiology and Community Health 61, no. 2 (2007).

${ }^{43}$ Dacey, Baltzell, and Zaichkowsky, "Factors in Women's Maintenance of Vigorous or Moderate Physical Activity.", Ball et al., "Personal, Social and Environmental Determinants of Educational Inequalities in Walking: A Multilevel Study."

${ }^{44}$ Dacey, Baltzell, and Zaichkowsky, "Factors in Women's Maintenance of Vigorous or Moderate Physical Activity.", Segar et al., "Midlife Women's Physical Activity Goals: Sociocultural Influences and Effects on Behavioral Regulation.", Robyne Garrett, "Negotiating a Physical Identity: Girls, Bodies and Physical Education," Sport, Education and Society 9, no. 2 (2004).

${ }^{45}$ McLean and Teague, "Obstacles to Action: A Study of New Zealanders Physical Activity and Nutrition."

${ }^{46}$ Sullivan et al., "Obstacles to Action: A Study of New Zealanders' Physical Activity and Nutrition Profiling Busy and Stressed.", Henderson, "Women, Physical Activity, and Leisure: Jeopardy or Wheel of Fortune?.", McLean and Teague, "Obstacles to Action: A Study of New Zealanders Physical Activity and Nutrition."

${ }^{47}$ Henderson, "Women, Physical Activity, and Leisure: Jeopardy or Wheel of Fortune?."
} 
from external factors or as a means to an end, such as participating in physical activity to lose weight, for social approval or maintaining health and fitness. ${ }^{48}$

Self-efficacy is another significant consideration for women participating in physical activity. This concept is based on social cognitive theory associated with Canadian psychologist Albert Bandura and broadly refers to the belief in ability to be able to carry out a certain activity. The key aspects of a theory of self-efficacy include the origins of efficacy beliefs; their structure and function; their diverse effects; the processes through which they produce these effects; and the modes of influence by which efficacy beliefs can be created and strengthened for personal and social change. Social cognitive theory is fixed in an agentic perspective. ${ }^{49}$

Bandura goes on to state that the efficacy belief system is the foundation of human agency, and that unless people believe they can produce a desired effect by their actions, they will have little incentive to act or to persevere in the face of difficulties. Whatever other factors serve as motivators, they are first rooted in the core belief that one has the power to effect changes by one's actions. ${ }^{50}$ In physical activity terms, it refers to whether a person feels they can be successful in undertaking physical activity in the first instance and if they feel they have the appropriate skills to do so. Further to that is the belief about whether they can be successful in maintaining the levels of physical activity necessary to experience any physical or emotional benefit.

Ball et al. (2007) found that cognitive variables (self-efficacy) remain the strongest predictors in leisure-time walking for example. ${ }^{51}$ Similar findings from the Phongsaven et al. (2006) analysis of the 'Obstacles to Action' data revealed that selfefficacy for participation in physical activity exerted the largest association with

\footnotetext{
${ }^{48}$ Lorna Haughton-McNeill et al., "Individual, Social Environmental, and Physical Environmental Influences on Physical Activity among Black and White Adults: A Structural Equation Analysis," Annals of Behavior Medicine 31, no. 1 (2006b).

${ }^{49}$ Albert Bandura, "Social Cognitive Theory: An Agentic Perspective," Annual Review of Psychology 52 (2001).

50 _ "Swimming against the Mainstream: The Early Years from Chilly Tributary to Transformative Mainstream," Behaviour Research and Therapy 42 (2004).

${ }^{51}$ Ball et al., "Personal, Social and Environmental Determinants of Educational Inequalities in Walking: A Multilevel Study."
} 
physical activity behaviour. ${ }^{52}$ Similarly, Haughton-McNeill et al. (2006b) also found self-efficacy was the strongest direct correlate of, and has the greatest total effect on, physical activity ${ }^{53}$, thereby illustrating the value of Bandura's theorising on the concept of self-efficacy as the basis for physical activity behaviour.

Motivation and self-efficacy are linked, as the concept of self-efficacy plays a key role in motivation. Haughton-McNeill et al. (2006b) illustrate this as they indicate that although extrinsic motivation may provide reasons for initiating an exercise or a physical activity programme, it is intrinsic motivation that is significantly associated with adherence over time. Having intrinsic reasons for engaging in physical activity, such as enjoyment, may increase one's confidence in the ability to be physically active. ${ }^{54}$ Furthermore, a recurring theme in Henderson's research on women and physical activity (both from a leisure studies and a health perspective) is a notion of enjoyment associated with intrinsic motivation. Participating in physical activity for enjoyment is also commented on by other researchers. ${ }^{55}$

Studies have found that enjoyment seems to be the biggest motivator, and higher levels of intrinsic motivation are related to higher levels of physical activity ${ }^{56}$ but that extrinsic motivation such as approval from others is not. This notion of enjoyment is characteristic of leisure and is explored through various leisure studies concepts. According to Hamilton-Smith (1992), it is widely accepted that leisure is a social construct. ${ }^{57}$ Haywood et al. (1995) takes this a step further by stating that leisure cannot be fully understood as something separate from the society and culture in which it is experienced. ${ }^{58}$ Given that, leisure is open to many possible interpretations and therefore is not an easy concept to define as it will have different meanings for

\footnotetext{
${ }^{52}$ Phongsavan, McLean Grant, and Bauman, "Gender Differences in Influences of Perceived Environmental and Psychosocial Correlates on Recommended Level of Physical Activity among New Zealanders."

${ }^{53}$ Haughton-McNeill et al., "Individual, Social Environmental, and Physical Environmental Influences on Physical Activity among Black and White Adults: A Structural Equation Analysis."

${ }^{54}$ Ibid.

${ }^{55}$ Ball et al., "Personal, Social and Environmental Determinants of Educational Inequalities in Walking: A Multilevel Study.", Allender Steven, Cowburn Gill, and Charlie, "Understanding Participation in Sport and Physical Activity among Children and Adults: A Review of Qualitative Studies.", Henderson, "Women, Physical Activity, and Leisure: Jeopardy or Wheel of Fortune?." ${ }^{56}$ Sullivan et al., "Obstacles to Action: A Study of New Zealanders' Physical Activity and Nutrition Profiling Busy and Stressed."

${ }^{57}$ Elery Hamilton-Smith, "Work, Leisure and Optimal Experience," Leisure Sciences, no. 11 (1992).

${ }^{58}$ Haywood Les, "Dimensions of Leisure," in Understanding Leisure (Cheltenham: Stanley Thornes, 1995).
} 
different people. However, leisure does have a number of associated concepts that are generally accepted and is in the first instance typically referenced with regards to work. Consequently, it involves non-work time generally conceived of as unobligated free time. Leisure can also involve a range of activities in which people choose to participate, like sport or games or TV watching. It is something that is freely chosen, instead of obligatory, and done for its own sake. It focuses on a quality of experience that involves an aspect of identity with the capacity to be and develop oneself. Leisure may also be conceived of in functional terms, both for the individual and for the wider society. This view of leisure is utilitarian and instrumental in nature. ${ }^{59}$ For the purposes of this research, leisure is characterised by a sense of freedom of choice, intrinsic motivation, enjoyment and relaxation, and in the context of people's every day lives involves discretionary or 'spare time' ${ }^{60}$

\section{Social environment factors that influence physical activity}

Patterns of physical activity have everything to do with how we live in the world. Despite a public discourse of physical activity situated in health, and a focus on individualism in health promotion, there has been more widespread acknowledgment of the affect of social and environmental features on physical activity. Social environment in this context is taken from Haughton-McNeill's (2006a) as the environment in which individuals live. The social environment is considered to influence behaviour by 'shaping norms, enforcing patterns of social control, providing or not providing environmental opportunities to engage in particular behaviours, reducing or producing stress, and placing constraints on individual choice'. ${ }^{61}$

Social environmental factors can be considered in many ways but are most often regarded in terms of social support and social networks. Social support features most widely as encouragement and motivation, as support for physical activity as well as in

\footnotetext{
${ }^{59}$ Ibid.

${ }^{60}$ Hamilton-Smith, "Work, Leisure and Optimal Experience."

${ }^{61}$ Lorna Haughton-McNeill, Matthew W. Kreuter, and S.V. Subramanian, "Social Environment and Physical Activity: A Review of Concepts and Evidence," Social Science \& Medicine, no. 63 (2006a).
} 
social networks and social roles for women. ${ }^{62}$ However, social support need not be defined solely in terms of motivation, as support can come from a number of avenues. Vrazel, Suanders and Wilcox (2008) confirms in their research on the social environmental influences on the physical-activity behaviour of women, that social support can be 'emotional', in the form of encouragement, 'tangible' in the form of childcare and household duties, and 'informational' through advice or guidance. ${ }^{63}$

The complexity of social relationships is also explored in the context of the social environment, as the social networks that can facilitate physical activity for women are the same networks and relationships that create barriers to opportunities for women's physical activity. ${ }^{64}$ Gendered social expectations and the effect of gendered social roles influence opportunities for physical activity significantly for women, ${ }^{65}$ and work and family life are noted as the biggest barriers. ${ }^{66}$ In the New Zealand context, Phongsavan et al. (2006) confirm the importance of taking into account gender differences when designing interventions aimed to address psychosocial factors for increasing physical activity. These factors, considered in relation to women's access to physical activity opportunities, are mainly in relation to various transitions and subsequent life stages and encompass the numerous social roles that women have as mother, partner, worker, and caregiver. This is expressed most in the literature under the 'ethic of care', which is acknowledged as a significant barrier affecting women and their opportunities for physical activity. ${ }^{67}$ However, continued significance is placed on having social support at the individual level, as research confirms it is

\footnotetext{
${ }^{62}$ Phongsavan, McLean Grant, and Bauman, "Gender Differences in Influences of Perceived Environmental and Psychosocial Correlates on Recommended Level of Physical Activity among New Zealanders.", Ball et al., "Personal, Social and Environmental Determinants of Educational Inequalities in Walking: A Multilevel Study.", Allender Steven, Cowburn Gill, and Charlie, "Understanding Participation in Sport and Physical Activity among Children and Adults: A Review of Qualitative Studies."

${ }^{63}$ JoEllen Vrazel, Ruth P. Saunders, and Sara Wilcox, "An Overview and Proposed Framework of Social-Environmental Influences on the Physical-Activity Behavior of Women," American Journal of Health Promotion 23, no. 1 (2008).

${ }^{64}$ Eyler et al., "Correlates of Physical Activity among Women from Diverse Racial/Ethnic Groups."

${ }^{65}$ Segar et al., "Fitting Fitness into Women's Lives: Effects of a Gender-Tailored Physical Activity Intervention.", Verhoef, Love, and Rose, "Women's Social Roles and Their Exercise Participation."

${ }^{66}$ Kei M. Nomaguchi and Suzanne M. Bianchi, "Exercise Time: Gender Differences in the Effects of Marriage, Parenthood, and Employment," Journal of Marriage and Family 66, no. 2 (2004).

${ }^{67}$ Yvette D. Miller and Wendy J. Brown, "Determinants of Active Leisure for Women with Young Children - An "Ethic of Care" Prevails," Leisure Sciences 27, no. 5 (2005), Nomaguchi and Bianchi, "Exercise Time: Gender Differences in the Effects of Marriage, Parenthood, and Employment.", Belinda Lewis and Damien Ridge, "Mothers Reframing Physical Activity: Family Oriented Politicism, Transgression and Contested Expertise in Australia," Social Science \& Medicine 60 (2005).
} 
consistently more important to have positive encouragement (to be physically active) for women than for men. ${ }^{68}$

The argument for the 'ethic of care' was theorised originally by Gilligan in her book 'in a different voice' (originally published 1982). Gilligan asserts that women have a different way of moralising, opting for an 'ethic of care' based on relationships. This is in comparison to men who generally moralise on a premise of justice to determine what is right and wrong, or good and bad. Women characterise what is right and wrong based on a complex web of relationships situated around a care perspective and sensitivity to the needs of others, and a responsibility to do so in a context where their needs come last. ${ }^{69}$ The 'ethic of care' is closely linked to obligations and expectations of women's various social roles. Interconnectedness within the roles and expectations and norms defining those roles lends themselves to influence individual behaviour choices. $^{70}$ This is evident in Jenkins et al.'s (2006) study of exercise barriers faced by first time mothers in New Zealand, as their group "nonresumers' (named for no longer participating in regular physical activity), indicated that many of the barriers associated with their return to exercise 'related to their perceived role as mother'. ${ }^{71}$

\section{Physical environment factors that affect physical activity}

A significant feature of ecological theory as it applies to physical activity is the role that the physical environment plays in influencing individual behaviour choices. This recognition comes somewhat later in research on physical activity and subsequently there is less empirical evidence related to it. However, it has become instrumental in the ecological approach in physical activity research. According to Sallis, Bauman

\footnotetext{
${ }^{68}$ Vrazel, Saunders, and Wilcox, "An Overview and Proposed Framework of Social-Environmental Influences on the Physical-Activity Behavior of Women.", Bess H. Marcus and Leigh Ann H. Forsyth, "Tailoring Interventions to Promote Physically Active Lifestyles in Women," Women's Health Issues 8, no. 2 (1998).

${ }^{69}$ Carol Gilligan, "Moral Orientation and Moral Development," in Women and Moral Theory, ed. Eva Feder Kittay and Diana T. Meyers (Totowa: Rowman \& Littlefield, 1987).

${ }^{70}$ Lewis and Ridge, "Mothers Reframing Physical Activity: Family Oriented Politicism, Transgression and Contested Expertise in Australia.", Miller and Brown, "Determinants of Active Leisure for Women with Young Children - An "Ethic of Care" Prevails.", Vrazel, Saunders, and Wilcox, "An Overview and Proposed Framework of Social-Environmental Influences on the Physical-Activity Behavior of Women."

${ }^{71}$ Carolyn Jenkins et al., "Exercise Barriers Faced by First-Time Mothers," New Zealand College of Midwives (Inc) 35 (2006).
} 
and Pratt (1998), physical environment features need to be considered 'because physical activity behaviour must be done in specific settings'. ${ }^{72}$ Physical activities take place in specific physical environments that are likely to influence the amount and type of activity that is undertaken. Thus, the concept of "behaviour setting" is particularly useful for ecological studies of physical activity.

The physical activity setting per se is examined in the context of the presence or absence of available programmes or facilities that may positively, or negatively, affect physical activity behaviour. In some behaviour settings, the goal is to remove impediments to activity, whilst in other settings the goal is to provide resources that facilitate physical activity. ${ }^{73}$ For example, qualities associated with the neighbourhood environment have to do with safe spaces and the presence of others. Traffic and the nature of the built environment and lighting are considered, as well as the presence of parks, walking and cycling trails, and indoor and outdoor places to exercise. ${ }^{74}$ The physical environment can also include features like terrain, weather, wind, and seasonal affectations like daylight savings. ${ }^{75}$

\section{Summary}

An ecological model provides a useful tool for understanding the various factors influencing women's opportunities for physical activity and as discussed in this chapter, current research identifies a variety of influences ranging from the physical environment through to the complex nature of social relationships. An 'ethic of care' and societal expectations of women's social roles are prevalent in the literature, as is recognition of individual attributes that influence decisions to be physically active. While much of this research has been carried out overseas, and in a number of different countries with their own socio-cultural contexts, there is remarkable

\footnotetext{
${ }_{72}^{72}$ Sallis, Bauman, and Pratt, "Environmental and Policy Interventions to Promote Physical Activity." ${ }^{73}$ Ibid.

${ }^{74}$ Billie Giles-Corti and Robert J. Donovan, "The Relative Influence of Individual, Social and Physical Environment Determinants of Physical Activity," Social Science \& Medicine 54, no. 12 (2002), Stewart G. Trost et al., "Correlates of Adults' Participation in Physical Activity: Review and Update," Medicine \& Science in Sports \& Exercise 34, no. 12 (2002).

${ }^{75}$ Henderson, "Women, Physical Activity, and Leisure: Jeopardy or Wheel of Fortune?.", Eyler et al., "Correlates of Physical Activity among Women from Diverse Racial/Ethnic Groups.", Im et al., "Midlife Women's Attitudes toward Physical Activity.", Sparling et al., "Promoting Physical Activity: The New Imperative for Public Health."
} 
consistency in terms of their findings regarding women's access to opportunities for physical activity. My study is well placed to make a contribution to the existing literature on women and physical activity. It provides research data from women in the New Zealand context using a qualitative study of women and physical activity. Both of these aspects are currently absent in the research on physical activity in New Zealand. 


\section{CHAPTER THREE: RESEARCH DESIGN}

\section{Introduction}

The leading notion behind this research study was to explore the barriers to women's opportunities for physical activity. This involves going beyond the universality of statements about being "busy" or "tired" and approaching the research problem at the level that appears to have the most impact: the experiences of the women in their dayto-day lives. This research design has been organised and developed around Crotty's four elements to the research process. ${ }^{76}$ According to Crotty, all research is based around what methods and methodologies we use to do research, and how we justify these choices. In doing so, we consider our epistemology, and theoretical perspective, and use them to guide our methodology and methods for how we do research. ${ }^{77}$ The purpose of this chapter is to present the methodological approach and research design used for the research project, and to provide a rationale for why I chose this approach. I will explain my method - focus groups - and explain the recruitment process undertaken for the sample. I will outline the protocol for how the focus groups were conducted, and what limitations were associated with using this method for data gathering. I will explain the analysis - thematic analysis - as well as ethical implications and considerations, and the credibility of the research. Finally, I will introduce the next chapter on results and findings.

\section{Epistemology}

Epistemology is the theory of knowledge. It is a way of understanding and explaining 'how we know what we know', 'what it means to know', and even 'what kinds of knowledge are valid and valued'. There are different perspectives for 'how we can know' that involve the dualism between subject and object. Constructionism promotes the idea that human beings make meaning by engaging with the world outside them. There is no meaning without a mind, or consciousness of something, and central to the constructionists' view, is that meaning is not a process of discovery, but comes from interaction. 'Meaning making' encompasses the notion of

\footnotetext{
${ }^{76}$ Michael Crotty, The Foundations of Social Research (Crows Nest, NSW: Allen \& Unwin, 1998). ${ }^{77}$ Ibid.
} 
intentionality, a reaching out into the world and an interaction between subject and object. It is out of this interplay that meaning is born, as human beings engage with reality and make sense of it. Further to this concept and central to this outlook is the idea that there is no one true or valid interpretation of reality as it is quite possible to make sense of the same reality in quite different ways, but all reality as meaningful reality is socially constructed. ${ }^{78}$

Interaction is a social process by nature, and constructionism focuses on the collective generation of meaning imbued with a primacy of relationships. This social dimension of meaning is central in social constructionism and social constructionism emphasises the role which culture plays in our interpretation of the social world. We are all born into a world of meaning; and we inherit the culture we are born into complete with its assumptions. This understanding of culture (Crotty borrows from Geertz) is a 'system of significant symbols' that acts as a guide for human behaviour. ${ }^{79}$ Things can be ascribed with meaning through culture, or not. Culture is the guide for the values we attach to things or whether we attach values at all. Institutions and community precedes us and we come to inhabit pre-existing systems. However, Crotty cautions us to be aware of a kind of restrictiveness associated with cultural understandings, and warns even to be suspicious of the constructed meanings that culture bequeaths to us. It is out of suspicion that many disciplines including feminism and critical theory evolve and, to paraphrase Oakley (taken from Crotty), a way of seeing becomes a way of not seeing. ${ }^{80}$ Feminism chooses to see in an alternative manner to what was simply inherited.

\section{Theoretical Perspective and Methodology}

This study is situated in feminism and critical ideals. Feminism best informs my research with women and physical activity by taking women's first hand accounts of their experiences as the points of departure for understanding their various meanings and experiences with physical activity and opportunities for it. This approach allows me to go beyond a narrow conceptualisation of physical activity in a standard health

\footnotetext{
${ }^{78}$ Ibid.

${ }^{79}$ Ibid.

${ }^{80}$ Ibid.
} 
model and focus instead on how women negotiate opportunities for physical activity within a social context. The goals of conducting research with women and physical activity are to make the reality of the women's lives more visible, by focusing on context to examine perception and values, and to understand better what is happening in their lives. Feminism is often used to document the structure of women's everyday lives and provide a description of women's experiences. ${ }^{81}$

A critical theory in the broad social science sense represents the social world by analysing the unspoken power relations of oppression. Critical theories suggest that the view of the world of the oppressed is different to that of the dominant group, and thereby a more valid alternative subjectivity. ${ }^{82}$ Research informed by critical theory has an emancipatory element to it and seeks to improve social conditions. Feminist and critical assumptions challenge the primacy of ideologies inherited from culture, and both perspectives hold that knowledge is best gained first hand. To make the meaning of women's lives more visible, it is necessary to analyse it from a woman's point of view. Feminist research takes this concept of 'situated knowledge', i.e. 'what is known' and the 'way it is known', as being reflective of the situation or perspective of the "knower". It acknowledges that those with relevant situated knowledge should be recognised as having the authority to testify about it. ${ }^{83}$ Since women are experts and authorities on their situation, the way they create and give meaning to their experience becomes central. It is useful to point out that there is no such thing as one feminist theoretical perspective and no one woman's feminist voice and consequently no desire to simply 'replace the orthodoxy'. Rather, there are many perspectives (e.g. Liberal, Marxist, and Radical) offering up competing theories on how, what, and whom to research, but all share the common value: to reduce, if not to eliminate, the injustice and lack of freedom that women experience. ${ }^{84}$

Feminist methodology is distinctive, as it has less to do with methods and more to do with the kinds of questions that are asked. Feminist research takes women's

\footnotetext{
${ }^{81}$ Green Eileen, Sandra Hebron, and Woodward Diana, Women's Leisure, What Leisure? (Houndmills: Macmillan Education Ltd., 1990).

${ }^{82}$ Elizabeth Anderson, "Feminist Epistemology and Philosophy of Science " in The Stanford Encyclopedia of Philosophy, ed. Edward N Zalta (2009).

${ }^{83}$ Ibid.

${ }^{84}$ Rosemarie Tong Putnam, Feminist Thought: A More Comprehensive Introduction, Second ed. (Boulder: Westview Press, 1998).
} 
situations, concerns, experiences, and perspectives as a basis for research and as Harding states, studying women from their own perspective. Issues that are important to women become the starting point for doing research. ${ }^{85}$ Many forms of research share the same methods; however, feminist research is underpinned and set apart by several features. Cook and Fonow (cited in Brayton, 1997) ${ }^{86}$ outline several basic principles for doing feminist research; among them, research that takes women and gender as a focus of analysis and that rejects the subject-object relationship in the research process. Harding recognises the part the researcher plays in the research process, and central to feminism (but not exclusively), the researcher is positioned as active in the research process and acknowledges that the beliefs of the researcher shape the research. Feminist research has a concern with ethics and an intention to empower women and change power relations and inequality, and values the knowledge held by the participant as expert knowledge. In taking a feminist approach, this research focuses on women's experiences, is transformative for women, and de-centres the power relationship in research by locating the researcher in the same critical plane as the research. It does not claim to speak for all women, but can provide new knowledge that is grounded in the realities of women's experiences to actively advance structural changes in the social world for women.

I use what Harding refers to as the methodological features ${ }^{87}$ of feminism to ground the research process, as context and purpose guide the choice of research tools and techniques. In thinking about context and situated knowledge, I employed an ecological model to explore why it is difficult for women in the 'Busy and Stressed' segment to be able to participate in physical activity. As discussed in the previous chapter, an ecological model focuses on not only individual behaviour but also on the interaction between the individual and the social and physical environment. Central to an ecological model is the assumption that behaviour cannot occur in one environment without having an influence in the other environments. Therefore, nothing is considered in isolation, and in using ecological theory to structure my

\footnotetext{
${ }^{85}$ Sandra Harding, "Is There a Feminist Method?," in Feminism \& Methodology, ed. Sandra Harding (Bloomington: Indiana University Press, 1987).

${ }^{86}$ Jennifer Brayton, "What Makes Feminist Research Feminist? The Structure of Feminist Research within the Social Sciences," http://www.unb.ca/PAR-L/win/feminmethod.htm.

${ }^{87}$ Harding, "Is There a Feminist Method?."
} 
inquiry, I have situated my research based on how the women in this study experience access to opportunities for physical activity.

\section{Method}

In order to understand the reality of women's lives behind the 'busy and stressed' statistics, I was keen to provide the context for them to be able to speak freely and get groups of women together to share their experiences. In gathering like-minded people in like-minded situations, I was aiming to provide a good opportunity for women to speak, initially about their own experiences but also in response to others' experiences as well. Group discussion may be preferable for women who may find a one-to-one situation intimidating and whose views can be validated by others' experiences. ${ }^{88}$ By bringing together groups of women from similar backgrounds, focus groups are useful for discovering what prompts certain behaviours, identifying barriers, and understanding how people think or feel about something. ${ }^{89}$

Focus group methodology is based on the understanding that the construction of meaning is never an individual process, and that meaning emerges from social interaction. ${ }^{90}$ Focus groups are typically used when attempting to better understand the 'how and why' behind a particular phenomenon. They are organised to explore a specific set of issues and are viewed as a collective activity that makes use of group interaction as part of the research data. ${ }^{91}$ I specifically chose focus groups for the dynamic that group discussion and interactions provide, as opposed to doing one to one interviews, for example. I chose focus groups as a research technique because they produce considerable, and often complex, information-rich cases from which I could learn a great deal about the types of major issues that affect women's access to opportunities for physical activity. Focus groups as a method fit in well with my methodological assumptions, as they could also function as a source of empowerment for the women to explore the barriers to their opportunities for physical activity

\footnotetext{
${ }^{88}$ Brayton, "What Makes Feminist Research Feminist? The Structure of Feminist Research within the Social Sciences."

89 "The Sage Encyclopedia of Social Science Research Methods," ed. M.S. Lewis-Beck, A. Bryman, and Tim Futing Liao (Thousand Oaks: Sage Publications Inc, 2004).

${ }^{90}$ Diane Beeson, "Nuance, Complexity, and Context: Qualitative Methods in Genetic Counseling Research," Journal of Genetic Counseling 6, no. 1 (1997).

${ }^{91}$ Jenny Kitzinger, "The Methodology of Focus Groups: The Importance of Interaction between Research Participants," Sociology of Health and Illness 16, no. 1 (1994).
} 
outside of their individual perceptions. This allows for a shift from an individual selfblaming psychological explanation to validation and mutual support in expressing feelings that are common to the group. ${ }^{92}$

Focus groups promote the idea of, and value in, investigating social situations through the subjective knowledge and lived experiences of the participants and allow for priority being given to the respondents' 'hierarchy of importance' expressed in the language, concepts, and frameworks they use to understand the world. ${ }^{93} \mathrm{~A}$ discussion group on the 'nuts and bolts' of everyday living and the reality of busy lives, helps provide greater insight on the sources of motivation and behaviour of the women involved in making their physical activity choices. Focus groups are important in this manner as they provide the opportunity to investigate a research problem further, and gather data, which cannot be obtained in other ways. ${ }^{94}$ These are the reasons why I chose focus groups as the method for this research.

There are, however, some drawbacks associated with conducting focus groups. Essentially the moderator influences (controls) the group's interactions in directing the discussion or maintaining the focus. Likewise, the group itself may influence the nature of the data it produces, as there may be a tendency towards conformity or polarisation. For example, participants may withhold what they might otherwise say in a more private setting, or alternatively participants may express more extreme views than they would in private. Thus, the presence of the group may affect what they say and how they say it. ${ }^{95}$ The quality of the data is dependent on the participant's willingness to interact, and there may be group monopolisers who take on a significant portion of the discussion. At the other end of the spectrum, some participants may give a sanitised version of events. Both of those last concerns I believe can be overcome by good group facilitation that guides the discussion and nudges everyone to speak at some stage, and to draw out responses.

\footnotetext{
${ }^{92}$ Kitzinger, "Qualitative Research: Introducing Focus Groups."

${ }^{93}$ _ Participants."

${ }^{94}$ Melinda Lewis, "Focus Group Interviews in Qualitative Research: A Review of the Literature," (2000), http://www2.fhs.usyd.edu.au/arow/arer/pdf\%20e-Report\%20version/002.pdf.

${ }^{95}$ David L. Morgan, Focus Groups as Qualitative Research (Thousand Oaks: Sage Publications Ltd., 1997).
} 
Other drawbacks are mainly to do with sample size and selection, although there are no hard and fast rules about the ideal sample size in qualitative enquiry. More importantly, the emphasis is on choosing the sampling strategy that best fits with the purpose of the study, that is suitable to answer what the researcher is asking and that fits within the resources available and the constraints being faced. ${ }^{96}$ Theoretically, saturation for this type of issue (barriers to opportunities to physical activity situated around work and family life) can be achieved with a relatively small number of groups. Generally, saturation is that point where data seems repetitive and there are no new concepts emerging from the data. ${ }^{97}$ As I am studying and posing a question within a specific framework, saturation is considered in that context. There is a logical pathway associated with the literature, data gathering and analysis to support my argument. ${ }^{98}$ Further to that, this study is based on a particular demographic and as such will not be representative of the population at large, nor even representative of all women in the population who may fit the demographic. Rather, taking account of the discussions of small groups of women from the 'demographic' on which the study is based is regarded as an opportunity to investigate some of the types of barriers that can be identified amongst the participants in relation to the research problem.

\section{Research population}

Gaining access to a particular group for a research project can be a major issue. Initially I had thought I would be able to gain access to the participants from the SPARC study. Participants in the Obstacles to Action study (2006) were invited to leave their contact details at the end of the questionnaire if they were interested in participating in any follow up research, thereby ensuring a ready population to choose a sample. Access to their sample would have been useful, not just because they were a ready population, but the women in that sample would already have been involved in research on physical activity and would have some experience with that. However, in light of a discussion with the Research Manager at SPARC, it became apparent that I would not be able to access the SPARC survey data. Initially what I thought was a

\footnotetext{
${ }^{96}$ Patton, Qualitative Research and Evaluation Methods.

${ }^{97}$ Davidson C and Tolich M, Social Science Research in New Zealand ed. Pearson, Second ed. (Auckland: Pearson Education New Zealand Limited., 2003).

${ }^{98}$ The Sage Handbook of Qualitative Research ed. Norman K. Denzin and Yvonna S. Lincoln, Third ed. (Thousand Oaks: Sage Publications Inc., 2005).
} 
methodological setback turned out to be fortuitous, as not being able to access the original data led to me having to re-create the research population.

The specific barriers identified by the participants in the 'busy and stressed' segment in the Obstacles to Action study first and foremost had to do with time issues ${ }^{99}$ situated around paid and unpaid work and family (childcare) responsibilities which in turn led to low energy and high stress levels. This was expressed as being too tired from work and too stressed by their busy lifestyles to participate in physical activity. ${ }^{100}$ Based on a number of identifying features, women for this study were recruited purposively. Purposive sampling cases are selected because they are thought to be 'information rich' and can provide the most insight about the phenomenon in question. Purposive sampling need not be considered in probability sampling terms (e.g. logic, purpose and sample sizes) but rather whether or not the purposive sampling supports the topic under study. Sampling concerns in this instance are considered in terms of context and are recognised for the quality that brings. Purposive in-depth sampling can provide meaning to the area of research that random probability cannot. ${ }^{101}$ Qualitative methods typically focus on small samples that permit inquiry into, and understanding of, a phenomenon 'in-depth'.

The logic behind selecting purposively is you decide the purpose you want the participants to serve, and you go out and find some. ${ }^{102}$ In this instance, the participants that could best serve what I wanted to find out were approached based on a number of demographic features including being engaged in paid employment or study, age 25-49, and not currently taking part in regular physical activity. Therefore the study was limited to women who fit those requirements, and the sample was selfselecting based on whether the women were interested in physical activity, and whether they chose to participate, or chose to enquire about participating. An information sheet was developed for potential participants to recruit a sample for the focus group discussions. (See Appendix 1)

\footnotetext{
${ }^{99}$ McLean and Teague, "Obstacles to Action: A Study of New Zealanders Physical Activity and Nutrition."

${ }^{100}$ Ibid, Sullivan et al., "Obstacles to Action: A Study of New Zealanders' Physical Activity and Nutrition Profiling Busy and Stressed."

${ }^{101}$ Patton, Qualitative Research and Evaluation Methods.

${ }^{102}$ Ibid.
} 


\section{Selecting Participants}

To collect the sample, I employed snowball sampling as a subsequent technique following purposeful selection, and actively recruited. Snowball sampling is a nonprobability technique where some people have more of a chance of being included in the sample than others and is often employed in qualitative research. In snowball sampling, a small number of individuals are identified as corresponding to a particular population with particular characteristics, for example (women aged 2549), and then are engaged to recommend similar individuals as potential participants for the study. ${ }^{103}$

Initially, information sheets were given to four women in the Social Science Research (SSRe) Applied Masters Thesis seminar programme ranging in ages from 23 to 46 for them to distribute. Additional information sheets were emailed to all primary and secondary schools in Wellington asking if the school would consider disseminating the information to women in the school community via a central notice board, school newsletter, email newsletter or web site. (See Appendix 2) I sent the same email message to the Ministry of Women's Affairs and they dispersed it to their networks, and women working in government departments. I also engaged the help of several friends to employ the same techniques amongst their friends and workplaces, and I did the same for my own networks. I actively recruited by handing out information sheets at several locations that I thought women in the demographic might frequent (e.g. craft show, swimming pool, playing fields and supermarket). Potential participants were encouraged to contact me via my details given on the information sheet, or prompted to pass on the information sheet should they not wish to participate in the research group themselves. Through the mix of outreach organisations and individuals I employed, I recruited a sufficient pool of respondents to choose a sample.

${ }^{103}$ Research Methods in the Social Sciences, ed. B Somekh and C Lewin (Thousand Oaks: Sage, 2005). 


\section{Overview of the sample}

Detailed characteristics of the sample are included at the beginning of Chapter Four; however, I will include a brief overview of the sample characteristics here. Overall, nineteen women participated in three focus groups. They ranged in age from 25-49, but the majority of the sample was from 35-49 as there was only one participant respectively from the 25-29 and 30-34 age groups. Nearly all of the women were married or living with a partner. They predominantly identified themselves as New Zealand European (there was only one non-European) and a large proportion of them had undertaken study above secondary school level. Many of the women had a child (or children) under the age of 18 living in the home, and the majority was working full or part time or undertaking study.

The irony does not go unnoticed in recruiting busy women to find enough time to attend a focus group. One of the more difficult aspects in conducting focus groups is they can be challenging to organise, for example, being able to find enough women who were able to attend a group at a specific night and time. There were also 'no shows' to contend with. Because of this, there is a certain pragmatism associated with recruiting for the focus groups. I arranged focus group opportunities as I received contact details from interested women, and over recruited to try to counteract any 'no shows'. As a result, I did not pay particular attention to representation of specific age groups across the demographic.

Some of the participants I had already met or knew someone who knew them. There was one woman who had previously participated in my Tuesday night cycling ride group, one woman I knew from university and a work colleague of my partner, for example. However, I was particularly careful not to include any close friends or women I might see on a regular basis, as I did not want to be privy to certain information they might not divulge to me otherwise. In addition, I was concerned that knowing some of the participants might influence what they were willing to say or share. I continued actively recruiting until I had enough participants for three groups. There were sufficient participants to be able to arrange additional groups, but three focus groups were adequate in revealing a full range of the particular types of 
answers concerning this issue, whereby by the end of the third group I judged there was no new information forthcoming.

\section{Autobiographical element}

I began by stating that this research has an autobiographical element to it. This is genuine with regards to my own experiences as a physically active woman. Having always been very physically active, I have good understanding of my own physicality and physical capabilities. I like to do many activities, but my particular fondness is reserved for cycling. I started riding bikes seriously when I was nineteen years old. It was the year my mother died and I had moved to the city with my Dad. I was not used to living in a city and catching buses, and I did not know how to drive, so I borrowed a bicycle (one of my siblings or cousins) for transportation and away I went. Truth be told, I found the activity rhythmic and distracting, and somewhat therapeutic during a very unsettled time. I still do. From then on, I was hooked, and over the years, I have cycled more kilometres than I can remember in countless ways. I have been involved in getting more women on bikes in some way, somewhere, ever since. My vocation in cycling extends from teaching little kids bicycle skills and road safety to working in cycling at the highest level in elite cycling in New Zealand. I continue to be involved as I currently host a Tuesday evening ride for women.

In researching women's opportunities for physical activity, I was somewhat concerned with a number of issues in studying a topic so close to my heart. In some instances, I felt I was hearing my own experiences. I could empathise with the women's stories about being too busy and too tired and having too many demands on their time. And I too am critical of an overarching prescription for 30 minutes a day. However, in being reflexive of the understanding of what it meant to be a researcher in this instance, I felt I was in a particular position where I could not (and did not) inject myself, and my experiences, into the discussions.

One of the central tenets of feminism when it comes to research is a commitment to decentre the power relations between the researcher and the participants in the research. As a woman interested in physical activity, I was conscious of presenting myself as one of them and as a feminist researcher I would have a similar goal - to 
decentre the power relations in the research relationship. Although I was very careful in trying to achieve this, it was very clear to me that the women regarded me as 'expert'. The women did invariably think that I knew everything, and that I was in a position to be able to offer solutions for how to manage their busy lives and gain some opportunities for physical activity, or shed some new light on the topic for them. Alas, I was not. I could only ask, probe, and encourage with as much empathy as I could muster.

Therefore, I was both an 'insider' and an 'outsider' in relation to the women in my study, and while I was not willing to allow too much of myself into the research study, I did feel my own perspectives could come into play in other ways. I accept the ideal that no research is value-neutral and my cultural assumptions and leanings inform not only my research question, but also the way in which I go about answering that question. My own experiences with, and connection, to physical activity over a life course can never be completely disassociated from what I do, in influencing what I research and how I approach it. An interest in women and physical activity in the first instance, undoubtedly guided my choice of topics, guided me in deciding what questions I could ask, and how to go about doing so. Also, essentially as someone who had 'been there and done that', I had a good understanding of the dynamics of what the women's daily lives could entail.

\section{Structure of Focus Groups}

The focus group discussions were held between September $17^{\text {th }}$ and October $21^{\text {st }}$ 2008. The group discussions were held at a neutral location - Turnbull House, 11 Bowen St., Wellington - on a weekday evening, and took between 90 and 120 minutes. The sessions were audio taped and there was a female note taker present to ensure a more complete data capture. The focus groups ranged from three to eight participants with 19 women overall taking part. Participants received a small gift or koha of appreciation for their involvement in the study at the end of the evening. With Group Two, the digital recorder failed and we (the note taker and I) were not aware of this until the group had finished and the participants had gone home. We conducted an immediate debrief of the focus group discussion, and were able to provide extensive notes for the group to review subsequently. Further, I sent a note to 
the Group Two participants to invite any additional feedback and reflection on the focus group. (See Appendix 3) The note taker's notes and the additional comments provided by the women were analysed in the same manner as the typed transcripts from Groups One and Three.

The focus group plan was taken from Richard Krueger's 'Focus Group Kit', (1998) and I used it particularly when I developed the questions. I also referred to it again for direction on analysing and reporting focus group results. I used a discussion guideline to facilitate the conversations (see Appendix 4). The topic guidelines consisted of seven general questions designed around three broad principles of the ecological model. The questions were adapted from the questionnaire used in the 'Obstacles to Action' study and addressed a number of themes including employment hours, housework, childcare and family commitments and free time, known factors that influenced women's opportunities for physical activity. The focus group discussions began with a general question to do with the women's perceptions of the term 'physical activity': So, what do you think of when you hear the term physical activity? The focus group discussions were lively and informative, and everyone engaged in the discussions at some stage.

I transcribed the audio tapes within a few days of the group discussion being held, and before the next group was scheduled. Before I began transcribing, I listened to the group discussion at least once to refresh and cement the course of the group discussions. This form of reflexivity was useful. First in continuously reflecting on and refining the line of questioning that could then be adapted for the next group, ${ }^{104}$ and, second, in aiding recall of the context of the group discussion, as well as the mood and dynamics of the respective group. It was an excellent way to begin familiarising myself with the data as a feature of early analysis.

\section{Ethics}

Ethical approval was gained from the Victoria University Human Ethics Committee (HEC) and is in accordance with the general principles of the Ethics Committee

\footnotetext{
${ }^{104}$ Though it should be mentioned that the line of questioning still followed the initial questions from the first group, and it was more a refining of follow up questions and probes to aid the discussion.
} 
found in the HEC guidelines. ${ }^{105}$ Particular attention was paid to providing sufficient advance information so that participants were aware of the study, but not so much information that could sway or limit the sharing of information, or cause participants to rush to solutions before the problem in question was fully articulated or understood. ${ }^{106}$ Preceding the group discussions, I gave a small introduction of background information to the research project and set the ground rules for how the group would run. The group at large, including the note taker and myself, were reminded of the confidential nature of the focus group discussions. At this time, the participants were requested to read and sign the consent to participation, and they could also elect to receive the results. (See Appendix 5) They were also requested to fill in a demographic questionnaire. (See Appendix 6) The researcher and note taker signed a confidentiality agreement at the beginning of each group as well. (See Appendix 7) The participants received a participant information sheet during the recruitment process, prior to electing to participate in the research. The information sheet addressed key issues such as an explanation of the research project; an explanation of how the groups were expected to be run; data security and confidentiality; and eligibility criteria.

\section{Credibility}

Credibility issues in qualitative research have more to do with the researcher than with sample size, and are addressed through the proccess of transparency as suggested by Rubin and Rubin (2005). Transparency concerns the process of conducting research, where the researcher is explicit, clear, and open about the assumptions made and the methods and procedures being used, such that a reader is able to see the process used to collect and analyse the data. ${ }^{107}$ An explicit notion of transparency that applies to the processes of qualitative research includes asking appropriate questions, choosing relevant research strategies, selecting participants,

\footnotetext{
${ }^{105}$ For a copy of the guidelines please see VUW Victoria University of Wellington, "Human Ethics Committee Guidelines," http://policy.vuw.ac.nz/Amphora! policy.vuw.ac.nz POLICY 000000001958.pdf.

${ }^{106}$ Patton, Qualitative Research and Evaluation Methods.

${ }^{107}$ David Hiles and Ivo Cermak, "Qualitative Research: Transparency and Narrative Oriented Inquiry," in X European Congress of Psychology (Prague, CZ: 2007). Herbert J. Rubin and Irene S. Rubin, Qualitative Interviewing: The Art of Hearing Data Second Edition. (Thousand Oaks: Sage Publications Inc, 2005).
} 
and justifying the methods of data collection and analysis and interpretation. The emphasis is on replicable procedures.

\section{Analysis}

Data analysis in the first instance is the task of preparing a statement about the findings. It should involve a systematic approach and follow a prescribed sequential, replicable process. ${ }^{108}$ I chose to use a procedure known as thematic analysis. Thematic analysis is a search for important themes in the data collected based on the question being addressed in the research and the theoretical position of the researcher. ${ }^{109}$ Analysis is related to the data gathering and shares qualitative constructionist assumptions. The research epistemology and methodology guides what can be said about the data and informs interpretation of it. What makes thematic analysis constructionist is that in this instance it is being employed to examine patterns of conditions that I understood as being socially produced.

Constructionism by its nature implies that nothing is individual but is the result of a social interaction. In the analysis, this is expressed as an interaction between the researcher and the data. Braun and Clarke (2006) support this approach when they state that:

'... an account of themes 'emerging' or being 'discovered' is a passive account of the process of analysis...it denies the active role the researcher plays in identifying the patterns or themes. ...the language of themes emerging can be misinterpreted to mean that themes 'reside' in the data...if themes reside anywhere, they reside in our heads from thinking about our data and creating links as we understand them'... ${ }^{110}$

The researcher is effectively speaking for the participants in the study. The concern about themes and issues is how to express them in a way that puts the women's voices into written text.

\footnotetext{
${ }^{108}$ Richard A. Krueger, The Focus Group Kit, 6 (Thousand Oaks: Sage Publications Inc., 1998).

${ }^{109}$ Catherine Pope, Nicholas Mays, and Jennie Popay, Synthesizing Qualitative and Quantitative Health Research (Maidenhead: Open University Press, 2007).

${ }^{110}$ Virginia Braun and Victoria Clarke, "Using Thematic Analysis in Psychology," Qualitative Research in Psychology, no. 3 (2006).
} 
Thematic analysis is mainly associated with a qualitative approach to analysing data in that it is primarily developed without a complete set of a priori themes to guide data extraction and analysis from the outset. ${ }^{111}$ It has, as its strong point, flexibility, in that it provides a means of organising and summarising the findings from a large body of research. This flexibility is also associated with its potential drawback as a method, as it intimates an unsystematic approach that lacks transparency. ${ }^{112}$ However, a lack of transparency can be addressed by clearly stating the steps taken during the process of analysis and outlining the analysis guidelines.

In the first instance, the process involves familiarising oneself with the data and begins with transcribing the data and noting down initial ideas. In reading and rereading the data, you can generate initial codes and develop potential themes from transcribed conversations. Patterns of experiences are identified and listed in the form of common ideas that are grouped to develop a pattern of findings. The findings are pieced together to form a comprehensive picture of the women's collective experiences, and written up as a statement, that comes from the data and that is supported by available evidence. ${ }^{113}$ However, I was reminded by Letherby (2003) of the importance not to over generalise the women's subjective accounts, or to claim an objective finding by simply amassing lots of similar subjective accounts. ${ }^{114}$ Thematic analysis is useful in combating this, as the flexibility of the approach helps provide a rich, detailed complex account of the data, whereby the data does not become limited and constrained by the type of analysis being used. ${ }^{115}$

I based my analysis on an example from Krueger (1998) and used it as a guideline for a systematic approach. I participated in the groups as a moderator and was privy to the discussions first hand. I typed the transcripts as soon as possible after each group. This involved firstly a complete account of the group discussions including the pauses in conversation, the 'umhs', 'ahms', and 'unh huhs'. I took all relevant comments in

\footnotetext{
${ }^{111}$ Pope, Mays, and Popay, Synthesizing Qualitative and Quantitative Health Research. 112 Ibid

113 J. Fereday and E. Muir-Cochrane, "Demonstrating Rigor Using Thematic Analysis: A Hybrid Approach of Inductive and Deductive Coding and Theme Development," International Journal of Qualitative Methods 5, no. 1 (2006).

${ }^{114}$ Gayle Letherby, Feminist Research in Theory and Practice (Buckingham: Open University Press, 2003).

${ }^{115}$ Braun and Clarke, "Using Thematic Analysis in Psychology."
} 
relation to each question from this main document. I used Microsoft Word to help manage the data as it became text, and bold-faced all questions to make them easier to find.

After all the groups were held and the transcribing completed, I began the analysis by examining the data question by question across the three groups. I employed a computerised version of a "Classic Analysis Strategy" also known as a "long-table analysis'. First, I colour-coded the responses from each group, e.g. yellow for Group One, green for Group Two and blue for Group Three. I then 'cut and pasted' the relevant responses from each group for each question and ended up with a master document of responses particular to each question. ${ }^{116}$

Next, I examined all the responses question by question, looking for overall themes or patterns. I was thinking about what the women were saying, how they were feeling and what seemed important to them. I looked for themes and how the groups compared, whether issues were raised similarly across groups, or whether there was something raised in one group and not the others, and if so, how I should treat this. I also considered which bits of the conversation were most effective to illustrate what the women were saying. This led into the inevitable struggle associated with what Mary Anne Casey refers to as 'the art of analysis': capturing the overall themes and the meaning behind them in a manner that really describes what I have learned from the women who participated in my groups. ${ }^{117}$

Care was taken in addressing issues of trustworthiness. The study was conducted in accordance with established procedures for qualitative inquiry. Relevant sources of information and literature were used to inform the study. Transparent procedures were employed throughout. The focus groups provide in-depth data on the issues I was seeking to understand, and the issues are further supported by existing literature from a several fields.

\footnotetext{
${ }^{116}$ Richard A. Krueger and Mary Anne Casey, Focus Groups Second Edition: A Practical Guide for Applied Research (Thousand Oaks: Sage Publications Inc., 2000).

${ }^{117}$ Krueger, The Focus Group Kit, 6.
} 


\section{Summary}

In this chapter I have outlined how I made use of Crotty's four elements of the research process. I consider an epistemological position based in social constructionism to be relevant for how I chose my theoretical perspective founded in the concept of a primacy of relationships for how we make sense of the world we live in. I have presented the methodology and methods chosen on this basis as well, and provided a rationale for doing so. The recruitment processes and sample characteristics have been described, as well as the protocol for how the groups were run. The data from the focus groups are presented in the following chapter, broadly around two categories of themes that fit within the ecological model; personal factors (which include socio-demographics, health and psychological factors) and environmental factors (which include both the physical and social environment). Both general categories have been examined and explored, and are presented with regards to the types of barriers they present to women's participation in physical activity. 


\section{CHAPTER FOUR: FINDINGS AND DISCUSSION}

\section{Introduction}

This chapter presents the characteristics of the sample, and provides a profile of each of the women who participated in the focus groups, to establish context. I present an overview of the focus group discussion used as the method of data collection, beginning with the perceptions of physical activity. An analysis of the findings, using thematic analysis, was conducted according to the three research objectives as follows:

- To explore the social environment factors that support and influence opportunities for physical activity, for example family, and paid and unpaid work commitments

- To investigate motivation - intrinsic and extrinsic, and personal factors such as attitudes, meaning and perceived benefits of physical activity

- To consider current behaviour and patterns of physical activity, how this changes and in what context. ${ }^{118}$

The findings are presented concurrently with a discussion of each of the research objectives and include a discussion of barriers to physical activity in general. Finally, I will briefly summarize my findings and introduce the final chapter on conclusions and direction.

\section{Characteristics of sample}

Participants in the three focus groups consisted of 19 women recruited purposively using a snowball sampling method. The women who participated in the focus groups were between the ages of 25 and 49, and nearly all of them were married or living with a partner. They predominantly identified themselves as European, and a large proportion of them had undertaken study above secondary school level. Many of the

\footnotetext{
${ }^{118}$ McLean and Teague, "Obstacles to Action: A Study of New Zealanders Physical Activity and Nutrition."
} 
women had a child or children under the age of 18 living in the home, and the majority were working full or part time or undertaking study. (See Table 1 below)

Table 1: Characteristics of Sample

\begin{tabular}{|c|c|c|c|}
\hline \multicolumn{2}{|c|}{ Characteristics of Sample*: Table 1} & & \\
\hline \multicolumn{2}{|c|}{ * Total sample $=19$ Participants } & & \\
\hline \multicolumn{2}{|l|}{ Age Range: } & Children $<18$ living in the home & \\
\hline $25-29$ & 1 & Yes & 13 \\
\hline $30-34$ & 1 & No & 6 \\
\hline $35-39$ & 5 & & \\
\hline $40-44$ & 6 & & \\
\hline $45-49$ & 6 & & \\
\hline \multicolumn{2}{|l|}{ Ethnicity } & \multicolumn{2}{|l|}{ Highest Education Qualification } \\
\hline NZ European & 11 & Some Uni/Polytech & 2 \\
\hline British European & 6 & Uni/Polytech degree & 9 \\
\hline Other European & 1 & Post Graduate Study & 6 \\
\hline Other & 1 & Did not answer & 2 \\
\hline \multicolumn{2}{|l|}{ Partnered Status: } & \multicolumn{2}{|l|}{ Work status: } \\
\hline Single & 1 & Working f/time in paid employment & 10 \\
\hline Married/Living with Partner & 15 & Working p/time in paid employment & 6 \\
\hline \multirow[t]{2}{*}{ Separated/Divorced } & 3 & Student (full/part time) & 1 \\
\hline & & Did not answer & 2 \\
\hline
\end{tabular}

However, to simply list or categorise the participants does nothing to denote the contemporary arrangements present in the family and relationships makeup. Several women were the main breadwinners for their families and their husbands were primary caregivers. As well, there were women who worked while husbands studied or re-trained, and women who parented alone and worked or studied full time. There was also a great range in the numbers and ages of children. There were single women who did not have any children, and married women without children or children who were already grown and left home. The number of children currently living in the home ranged from two to five children. Below I will provide a further description of the sample participants, presented as individual profiles for each of the women who participated in the discussions. The profiles are provided as a means of establishing the context for the women and to illustrate some of the complexity associated with their daily lives. All participants are presented under pseudonyms and where 
included, any conversation relating to a particular participant is presented in italics and indented.

\section{Participant profiles}

Annabel works part time and attends a fitness class once a week with a group of women who continue to meet despite just losing their trainer. She is married with two children, a five year old at primary school and a three year old. Her partner is a full time student.

Betty works full time, is married and has one child over eighteen no longer living at home. She has a spinal condition that keeps her from doing any physical activity that has impact. She swims and cycles, but is not doing much of either at present.

Carol works full time and has currently undertaken a new role, which involves setting up a department, which in the short term at least requires a lot of time and commitment. She is married and has two children aged four and almost six, and her partner is the primary caregiver and homemaker.

Donna works full time as a teacher and part time as a tutor for special needs children. She lives near her work, but most likely has after school commitments and materials to carry which prevents her from walking. She is married and has three sons, an eleven year old at intermediate school and fourteen and seventeen year olds at college. She supported her partner through career change that involved schooling and an apprenticeship.

Evelyn works full time and participates in a work - based walking programme. She has a work place "walking buddy" whom she is inspired by, and walks with, most lunchtimes. She is single (separated or divorced) and has two children at school, a nine year old and an eleven year old.

Frances has just given up full time work as a small business owner. She belongs to a fitness group that meets once a week and attends with her friend 
for motivation. She also gardens. She is married and has two children, a nine-year-old girl at primary school and a two and a half year old toddler.

Glennys works full time, is currently recovering from a foot injury, and as a result is not doing anything right now. She is single (separated or divorced) and does not have any children. She previously had her good friends and training for a triathlon as a goal to motivate her.

Harriet works full time and lives outside Wellington. Her office is located on two levels so she spends at least some of her day moving around, and her work takes her outside, which gives her more opportunity for moving about. She used to be a competitive swimmer at varsity level but is not doing much of anything now. She is married, she does not have any children and her partner works and studies part time.

Isabel works part time. She is married and has five children, four of them are at school, intermediate and college, and one is over eighteen. She comes from a very active background and used to be an avid sports woman. She thinks organised exercise is too expensive, and that society does not appreciate what she refers to as "Mum exercise".

Julia loves exercising and enjoys an endorphin "high". She works in an organisation that has a commitment to physical activity and fitness, and is well supported by her employer. She is married, and has two children who no longer live at home. She works full time.

Karen enjoys physical activity in a social context best, and likes to participate in team sports. She is not doing so at present because she feels she is not fit enough and is concerned with an aging body. She is married and has one child living overseas. She works full time and her partner works full time as well.

Laura used to be quite a fitness fanatic, but is not doing much of anything right now. She is married and has a one year old. She has recently returned to 
part time work as a teacher and appreciates how much energy she expends moving around the classroom and teaching.

Madelyn works full time. She is single and has one child at primary school. She is not doing much at present and wishes she could do more. However, she is aware that any extra commitment would result in her spending more time away from her daughter and she is reluctant to do this. She tends to be more active in the summer.

Nora works full time. She previously enjoyed the structure that came with participating in school sport. She is not doing much of anything at present, and does not like gyms but likes to garden. She is living with her partner; she does not have children, but has three cats and a dog.

Olinda works part time. She is not doing anything with any regularity right now, but has an exercise machine at home. She grew up in a very active environment. She is married and has three children. Two of the children are school age and one is a toddler. She prefers to exercise on her own.

Patricia is a full time post-graduate student. She is single (separated or divorced) and has two children, one at primary school and one at intermediate. She walks when she can, and tries to park her car farther from her destination to fit some physical activity into her day.

Queenie works full time as a teacher and head of department. She has a back injury and is not doing much of anything outside of an occasional swim at present. She is married and has two children at primary school. Her husband is currently building their house and additionally is at home with the children.

Rhonda works part time. She has a commitment to a fitness class with her friends once a week. Other than that, she walks her children to school. She is married and has two children at primary school. Her partner works full time as a teacher. 
Sandra works part time, four days a week. She walks to work twice a week in an attempt to fit some physical activity into her routine. She is married and has three children at primary school and her partner works full time as well. She enjoys being physically active with her children and partner.

\section{Perceptions of physical activity}

In contextualising physical activity for the women involved in the study, first it is appropriate to look at which factors have an effect. Questions to do with who?, what?, when?, where?, and why? are useful in gaining an understanding of how the women get or gain opportunities for physical activity. In opening the group discussion, the initial question explored their perceptions (or understanding) of physical activity and what that meant. Many of the responses had to do with the perception that physical activity specifically meant exercise or was indicated by naming specific activities (like walking, swimming, or the gym):

'...yeah, first off I would think of ...gyms, running, some kind of extra activity, outside of day to day, but I suppose if you stopped and think about it, it could include all your day to day activity'...(Glennys, single no children, works full time).

Others indicated that their idea of physical activity was simply 'anything moving':

'...it means physical activity, just moving, just doing something but not necessarily exercise but moving'... (Evelyn, single, two children, works full time).

Many of the women differentiated between physical activity and exercise. Qualities that they associated with exercise had more to do with how much effort you put in, how long you did the activity for, and if your heart rate was raised. Exercise was also regarded as a much more structured activity that was used for fitness or training. Physical activity, like walking between buildings, for example, was seen as physical activity in the sense of getting from A to B and for the usefulness of that activity: '...even though I walk very briskly (laughing) even when it's hot and you know I carry lots of things, so it probably is exercise, I don't think of it as exercise'...(Carol, married, two children, works full time). 
A number of participants regarded daily activities as physical activity, for example:

'...we keep thinking that exercise needs to make us sweat, I've started thinking I've cleaned the house or walked the kids to school and that counts'...(Patricia, single two children, studies full time).

Particular activities, like walking to the bus, were for some participants a conscious effort at moving about in an increasingly sedentary lifestyle. 'Moving about' could count on both a physical and social level, as new technology like email for example is sedentary, and cuts one off from people. Other daily activities, while they could be regarded as physical activity, were not considered as exercise, though there were varying degrees of thought on this. For example, day-to-day activities could be regarded as physical activity if one undertook them in a specific way for instance strenuously, 'or if you spent a hour hoovering... but who does that?' Housework was not regarded as either physical activity or exercise. Exercise was consciously making an effort, whereas housework was not sufficient to actively improve fitness. While it might maintain, or slow down a loss of fitness, but there were no endorphins to make you want to keep going: ... and I think there's a whole thing around people say ...endorphins or things like that (yep) things that release when you do exercise...that make you feel good and... want it even more (laughing, group laughing).. I don't think I ever do housework for its feeling, like doing chores and racing up and down and yeah'... (Sandra, married, three children, works part time)

For some, there was no difference between physical activity and exercise as both were something you had to set aside time to do.

There was also a critical element expressed about being told what to do and how much:

Harriett: 'I don't know if it's the media or the fitness industry but they say you need to do 30 minutes ( $\mathrm{hmmm}$ ) it needs to be a 30 minute block and you need to have your heart rate at your fat burning... sort of 120,130 or higher for it to actually even count as exercise. You need to sustain that heart 
rate for 30 minutes. ( $\mathrm{hmm} \mathrm{hmm)} \mathrm{so,} \mathrm{I} \mathrm{guess} \mathrm{then} \mathrm{if} \mathrm{you} \mathrm{look} \mathrm{at} \mathrm{well} \mathrm{is} \mathrm{it} \mathrm{really}$ going out for a 20 minute walk, yeah is it?'...

Annabel: '...Well see you need an hour really don't you? You have to get changed, you have to get out there, you have to get back, stretch, have a shower, dry your hair'...

Harriett: '...And it takes ages, but based on the 30 minute block thing, the 20 minute walk doesn't actually do anything but is that true or is that just what they say?'...

Glennys: '...I'd argue that and say that anything is better than nothing'... (hmm, yep, yeah).

Or:

Madelyn: '...I think what would it take to motivate us, we used to get told do 20 minutes a day three times a week, now it's 30 minutes every day. Where's this all coming from? I think we have to be sceptical about the reasons why we're being told this, and why we should be made to feel guilty if we don't'... [do it ].

It is clear that there were many differing thoughts and opinions on what makes up exercise or physical activity, and in what 'counts' as such. Previous research has illustrated similar situations with regard to terms like 'exercise' and 'physical activity' that are poorly understood, or interpreted differently, even amongst people socialised in what Tudor-Locke refers to as 'mainstream white culture'. 119 Interpretation and meaning are formed in relation to the individual and their environment (context) so perceptions ranged from, having to do something specific for a certain amount of time, to simply 'moving about', which was considered 'good' as it directly combated being sedentary. Brookes and Magnusson's research on young adolescent women confirmed what they call 'an attachment of significance to contextual features'. Here a weekend walk could be intrinsically healthy, relaxing, challenging and enjoyable, whereas the same routine walk to get to school could be

\footnotetext{
${ }^{119}$ Catrine Tudor-Locke et al., "In Their Own Voices: Definition and Interpretations of Physical Activity," Women's Health Issues, no. 13 (2003).
} 
defined as having little value as it failed to have the above characteristics and was simply not fun. ${ }^{120}$

Respondents' comments suggested there was some pressure from media messages to be physically active. The women were aware of the benefits of being physically active, but promotional messages acted as pressure, making them feel like they should be more active. ${ }^{121}$ Some of the women felt guilty. If they did not have what was recommended as the right amount of time to participate in physical activity, they did not bother, and consequently were not able to comply. This introduces a sense of compulsion whereby the individual is made to feel like they have to do, or should do something for whatever reason, in this case because of health benefits. Not being able to participate or even not wanting to participate is accompanied by a feeling of guilt. Some participants had to look elsewhere to include activity in their lives as they did not seem to count the physical activity associated with day-to-day activity (with the exception of gardening) and chores were just chores.

\section{Personal factors that influence physical activity}

Generally, the women had positive attitudes to physical activity, and had an understanding of physical activity as having particular benefits. These benefits were expressed as mainly to do with health and well-being. Some women participated in physical activity in response to a medical professional's directive. Participants' reasons for being physically active had to do with feeling better mentally and physically, being fitter, having more energy, and sleeping better. This reasoning is extended to future health, for example:

'...I think of the future that the more I'm active now it's better for me long term'...

Or:

'...good investment for our future, for your family'...

\footnotetext{
${ }^{120}$ Fiona Brooks and Josetine Magnusson, "Physical Activity as Leisure: The Meaning of Physical Activity for the Health and Well-Being of Adolescent Women," Health Care for Women International 28, no. 1 (2007).

${ }^{121}$ Denise Leith and Susan Shaw, "Physical Inactivity in Leisure: Why Some Women Adopt Inactive Lifestyles," Journal of Applied Recreation Research 22, no. 4 (1997).
} 
Weight control, self-image and body image were also important, non-health related, benefits of participating in physical activity, feeling good 'about me' looking good, feeling more self-confident or having more self-esteem. Issues to do with weight involved participating in physical activity as a means of:

'...fighting fatness and obesity'...

'...weight control'...

'...stop me getting fat'...

'...fitting clothes'...

'...it's good to look good'...

These body image reasons also contained an element of 'should' statements 'cause I know I kinda should', and a reference to 'brownie points' quickly caught hold in one group. Brownie points were associated with the length of time spent being active. The example used was walking the dog, and whether or not it counted. For example, 45 minutes walking the dog was 'good' but 20 minutes walking the dog did not quite 'cut the mustard' in regards to having done enough, for a long enough time. This type of reasoning is infused with ideas of what is good and bad and seems to be linked to expectations to do with complying. In this way, exercise or physical activity that may be motivated intrinsically, for example, for fun and may be a source of empowerment for women, now takes on a quality that is related to an element of obligation where it is engaged in for the benefit of others. ${ }^{122}$

Many of the women included the fun or social aspect of participating in physical activity as a benefit, as well as it being an opportunity to have time on their own. Participants said one of the advantages of being physically active was because it was social and fun and they enjoyed it, even after some effort to 'get going'. The enjoyment factor was enough to motivate them to go and do something like a class or a bike ride. Also in this category were the ideas of a change of scenery, getting to do new things with the kids, or spending quality time with the kids, exploring, taking family bike rides and physical activity linked into social life.

Physical activity was also regarded as a way to have 'time out'. 'Time out' was referred to as 'me time'; 'my time alone'; or 'a sense of escape from the rest of my

\footnotetext{
${ }^{122}$ Nanette Mutrie and Precilla Y. L. Choi, "Is 'Fit' a Feminist Issue? Dilemmas for Exercise Psychology," Feminism Psychology 10, no. 4 (2000).
} 
life'. Time spent doing physical activity was described as relaxing, a time to be creative:

'...I think I come up with all my best ideas when I'm out for a walk or a run'... (Rhonda, married, two children, works part time)

with no interruptions:

'...I work at a school and am always surrounded with people, my office is shared with others, it sounds selfish, but at the end of the day I need my alone time. It's something you can start and finish in your day without being interrupted'... (Laura, married, one child, works part time).

The idea of 'me time' (expressed here as 'free time') was taken to mean time that was purely for themselves, and could be spent on various types of leisure activity such as reading a book, choir or physical activity, for example. 'Free time' is most often used to describe the amount of time people have left over after they engage in the activities required of them in their daily life. It is regarded as residual time, and involves time spent doing things that are not connected to paid employment or with maintaining home, family, or self. Free time often gets used interchangeably with leisure time, but it should be recognised that leisure time has a more restricted meaning in that it refers to that portion of your residual time that you would use for leisure or recreation activities. $^{123}$

The women often associated their me-time with physical activity and they used physical activity in a variety of ways to re-energise, de-stress, refresh and as time to themselves. Often the activities were solitary, as the women spoke of a need to clear their thoughts or their heads for example. This time was also used for 'treats' (like having a 'facial') that contained an element of pampering or pleasure. The concept of 'me time' and enjoyment links in with the more functional or instrumental view of physical activity, as many of the women tended to disregard that meaning of physical activity. There was recognition that occupational or household activities may add up, but generally, those kinds of activity were not regarded as the kind of physical activity in which they wished to participate. The feeling was that when they did something physical it was because they wanted to, and enjoyed doing so, not because

\footnotetext{
${ }^{123}$ Roger C. Mannell, "Encyclopedia of Leisure and Outdoor Recreation," in Encyclopedia of Leisure and Outdoor Recreation, ed. John M. Jenkins and John J. Pigram (London: Routledge, 2003).
} 
they were looking to 'make do'. In some cases, this time included being active with the family or the children:

'...it's nice and I enjoy it and it's good for me and it's fun hanging out with the kids but, I wouldn't classify it as my exercise for the week'...(Annabel, married, two children, works part time)

Of course, there is nothing wrong with physical activity being useful. However, it is questionable if the reasoning is that worth and value only comes from being useful. In this approach, the intrinsic value of movement is traded for an extrinsic value. This results in a shift from movement for enjoyment and play to movement for work, including a shift away from promoting movement as meaningful in its own right, to regarding activity as a duty.

There were a number of differing attitudes on the value of incidental or functional physical activity, in that many of the women in the study did not like the idea of incidental physical activity that could add up to their 30 minutes a day. Those women held a view of physical activity as being a kind of leisure time. However, while the women may want physical activity as leisure time, they may still also regard incidental activity as being useful if not obligatory. Some participants wanted the value in 'Mum exercise' to be socially recognised, as parenting and caring work is hardly to be regarded as sedentary or inactive. Of concern here is the issue of societal stereotypes associated with being a good wife and a good mother. These roles have a significant amount of activity associated with them that still falls largely to women. The concern is that through societal influences, women may continue to be constrained in their opportunities to physical activity that results in a loss of control over how they gain opportunities for physical activity and what kinds of activity are undertaken. This is well supported in the literature, as Lewis and Ridge (2008), Jenkins (2006) and Vertinsky (1998) all make arguments for women who are constrained by socio-cultural stereotypes associated with being a mother. ${ }^{124}$

While the women were extrinsically motivated in many ways, they were more motivated intrinsically. They wanted to do physical activity because it was

\footnotetext{
${ }^{124}$ Lewis and Ridge, "Mothers Reframing Physical Activity: Family Oriented Politicism, Transgression and Contested Expertise in Australia.", Jenkins et al., "Exercise Barriers Faced by FirstTime Mothers.", Patricia Vertinsky, "Run Jane, Run: Central Tensions in the Current Debate About Enhancing Women's Health through Exercise," Women \& Health 27, no. 4 (1998).
} 
something to be enjoyed, in and of itself, this is a clear example of intrinsic motivation. They did not see physical activity as strictly being health - related (though they did recognise the health benefits of being physically active) and did not want to forego the leisure aspect of their time spent being active. This means overriding other factors such as doing it for health and wellness, or as a good role model, or for the children, or following the doctor's advice. In this context, physical activity was less about anything else and more about them. They participate because it is something they want to do - they enjoy being able to express themselves as physical beings, as a part of who they are and how they choose to spend their leisure time. They are active because they want to be and wish they had more time to be so.

Having said that, the majority of the women reported, for a variety of reasons, they were less active now than they used to be. Many women said that although they felt physical activity was important; it did not appear to be much of a priority. This was confirmed by comments like:

'...And that's also the priority $(\mathrm{hmm}) .$. for some reason it seems to be even if it is something we enjoy we still put it as a lower priority and therefore if something's gotta go it's the exercise that goes'...(Rhonda).

'...My kids have gone, I have the time, but no energy, and work seems to take priority'... (Julia).

One woman did not think personally that it was important, but added that she knew it should be. She gave an example of a friend in similar circumstances to herself who still finds the time to fit in physical activity:

'...Yep she[my friend] makes a point of going for 2 hour run at the weekend you know is quite good at doing that and... and I don't... and so is it important?...

...I'm thinking maybe I don't think it's as important as my friend who obviously does and is making time for it..., ahm yeah, because otherwise I think I would make time for it'...(Rhonda.)

There was also a contingent of women who indicated they were more active now than they used to be, though they felt they would still fall outside the national guidelines. 
Many of the women have been active for much of their lives, during either childhood or sport at school, while some had only become active more recently. One woman described her experiences with physical activity in terms of:

'...before children and after children' ... (Carol)

and another:

'... and then everything stopped for a few years'... (because of children)

(Annabel).

Some women described their past experiences as being good, even when they described their school experiences as ones in which they were not good at physical education or being a 'team sport player'. One woman stated that she did not have any past experiences with physical activity at all.

Despite not being able to do 'much now', generally most women did see their situation changing over the next few years. Many of their comments were in regards to children getting older and, as parents gaining more independence from them, to be able to do more. A similar group of responses was also in relation to children getting older and then being able to do more with them. For some, who did not think their situation was likely to change, one woman's response had to with a lack of motivation:

'...I'm just not reliable? I'm not... and yeah, I don't know when I will be, hopefully one day'... (Harriet, married, no children, works full time).

While another respondent was aware, that she was not putting herself first:

'...but it's, for me I have to learn to say no, and say look I have to do some physical exercise for me'...(Donna, married, three children, works full time).

The overall message here is that the women who participated in the focus groups are too busy and over committed for the kind of self-care that they associate with participating in physical activity. It is clear that many of the women had the knowledge and awareness of the benefits of physical activity. Yet this knowledge is not enough to make them change their behaviour, a finding that is well supported by 
past research. ${ }^{125}$ These women knew the benefits of physical activity, health and otherwise, and they knew they could be active in many ways. They also knew that activity could be added up or not, depending on how one viewed that personally.

My interpretation of this is that the demand created by work and family, among other things, feeds into a state of decreased self-efficacy. The women do not perceive that they can attain the suggested physical activity levels or fit some physical activity time into most days. This evidence is substantiated by the most recent SPARC study (2008), which found that women could make all the necessary arrangements to participate in organised physical activity perhaps once a week. In fact, $80.3 \%$ of those who participated in at least one sport or weekly recreation activity were women. ${ }^{126}$ That is, they were able to make things happen by rescheduling, reshuffling, and planning for one time a week, but this was all that could be managed. There were good examples in the focus group discussion of women, who did this, but it appeared to be a one-time thing only, as they did not make those kinds of arrangements for more than that. Self-efficacy in this capacity seems to have more to do with being able to create the opportunity (time management) than it does with having the skills to be able to carry out a specific activity.

Ultimately, the women appear to choose to be physically active because they want to be and for the most part they like to be physically active and they enjoy it.

Enjoyment is a key feature supported in the research that is likely to influence continued involvement and participation in physical activity ${ }^{127}$ and this type of intrinsic motivation is often one of the strongest indicators of participation. ${ }^{128}$ Allender et al. (2006) found that fun and enjoyment rather than perceived health benefits (among other motivations) were reported more often as predictors of

\footnotetext{
${ }^{125}$ Trost et al., "Correlates of Adults' Participation in Physical Activity: Review and Update.", McLean and Teague, "Obstacles to Action: A Study of New Zealanders Physical Activity and Nutrition."

${ }^{126}$ SPARC Sport and Recreation New Zealand. "Sport, Recreation and Physical Activity Participation among New Zealand Adults: Key Results of the 2007/08 Active New Zealand Survey." (Place Published, 2008), http://www.sparc.org.nz/research-policy/research/national-surveys/200708-activenz-survey.

${ }^{127}$ Henderson, "Women, Physical Activity, and Leisure: Jeopardy or Wheel of Fortune?."

${ }^{128}$ Ball, "People, Places ... And Other People? Integrating Understanding of Intrapersonal, Social and Environmental Determinants of Physical Activity."
} 
participation and non-participation. ${ }^{129}$ Enjoyment may add to an increased sense of self-efficacy, as women who have a successful physical activity experience may feel empowered to try to make opportunities for more.

Access to opportunity for physical activity on the part of these women is based on doing something for themselves, as a way of recreating or rejuvenation without the usual commitments of their various social roles or in combining activities. Physical activity as a self-determined behaviour or activity is specific for many of the women in the study because it may serve as a source of self-expression, identity and selfesteem that involves choice. ${ }^{130}$ Therefore, in terms of some incidental activities or the social arrangements of using physical activity time with family, these were not as acceptable for the women as ways of achieving what they wanted to achieve from being physically active. Physical activity is valued for its capacity as personal recreation, away from other demands, as well as for the contribution it makes in enhancing emotional and physical wellbeing. ${ }^{131}$

\section{Social environment factors that influence physical activity}

Although not everyone received encouragement, encouragement and support came from a number of sources, such as work, media, medical professionals and recruitment, in a number of ways:

Annabel: '...My husband's hugely supportive... and the boys will even say oh, are you going to tonight, so they know that it's part of my routine and it's what I do'... (hmm hmm)

Frances: '...My daughter's the same (yes) ....she's quite interested..., 'so what exercise are you going to do tonight' and that's good because she doesn't see me sitting around on my bum doing nothing'...

\footnotetext{
${ }^{129}$ Allender Steven, Cowburn Gill, and Charlie, "Understanding Participation in Sport and Physical Activity among Children and Adults: A Review of Qualitative Studies."

${ }^{130}$ Ibid, Susan M. Shaw, "Conceptualizing Resistance: Women's Leisure as Political Practice," Journal of Leisure Research 33, no. 2 (2001).

${ }^{131}$ Lewis and Ridge, "Mothers Reframing Physical Activity: Family Oriented Politicism, Transgression and Contested Expertise in Australia.", Henderson, "Women, Physical Activity, and Leisure: Jeopardy or Wheel of Fortune?.", Dacey, Baltzell, and Zaichkowsky, "Factors in Women's Maintenance of Vigorous or Moderate Physical Activity."
} 
Glennys: '...From friends... particularly from the two that well, started me on all this in the first place ... you know we do sort of motivate each other so that's quite good for me'...

Donna: '...Having my boarder, her being female it was like we could go out and talk girl things. And not have males (oh yeah, you're in a house of boys, group laughing) listening to the discussions on periods and all of those sorts of things... we had that time and that was our let's go for a swim, do lengths, and have a natter while we do'...

Or:

Rhonda: '...Once a week I go with my friends to aqua deep class at the swimming pool and that's just for me, I'm not very good at self motivating, so I sort of manage to hook in with some friends... and we all go together in the same car and we have a good laugh you know, and it's that sort of social thing as well which for me works really well'...

Most commonly, support came from husbands or partners, other family and friends both by way of encouragement to do physical activity, - and in social support during physical activity - someone to participate with. Social support was sometimes more tangible with family members or partners taking on extra duties to help free up some time for the women. Many of the women thought tangible support was very desirable, as several of them made mention of how useful some help would be. Some of the women had good support and encouragement that did eventually become tangible support, though some said that this tended to be more serendipitous than planned or scheduled.

Other types of support and encouragement came from employers in the form of workplace activity programmes. Two of the women spoke about organised walking programmes, complete with pedometers. There were also other activity sessions provided such as boxing, squash and golf, and one woman had:

'...[a] really good environment at work, we have a gym, circuit training we can attend three times a week and Pilates, and it's all free and all the staff are supportive'...(Julia, married, working full time no children at home). 
As well, there were provisions for facilities like showers that were helpful in enabling employees to be more physically active, though it was less certain about how widely they were publicised or how well known the programmes or facilities were, or how the women perceived them. There was some discussion about employer gyms as a past experience that was very enviable.

Some of the women felt strongly that the employer had a significant role to play in providing an opportunity for working women to be able to accommodate physical activity more readily:

Betty: '...I think that the employer plays a large part actually,... if you feel your employer is supportive and encouraging of exercise at whatever level... then I think it makes it easy for you to do it... and you also probably don't have as much of the guilt feeling because it's an integral part of what you are doing and your employer sees it as actually adding value to your job rather than you taking time away from your job... [gave an example of an employer programme] ... and I used to think gosh that would make such a difference to how you approached exercise and where it featured in your daily planning,... made to be a part of, instead of an added extra, of your day... We need an Act passed (hmmmm) that all employers over a certain number of people (yeah) will provide some gyms and gym facilities'...

Evelyn: '...I think they need to...they probably are starting to look at those sorts of things and even more so... like child care ... facilities and things they need to hold onto ...employees especially with the market the way it is'...(yeah yeah)

Betty: '...well they are changing they way they think because um they're more open to part time you know managing, (yes working the hours, yep) managing that balance again' ( $\mathrm{hmm} \mathrm{hmm).}$

However, some women also spoke out against employer programmes with an argument based in equity:

'...and I think work... Human Resources has a plan that the company gives time off to exercise, but then there's the whole equitable thing? If some don't 
want to do it, do they still get the time off?'... (Nora, living with partner, no children).

There were also instances of negative encouragement (discouragement) and those who did not wish to have encouragement at all:

'...yeah it works for others, but when my partner encourages me he thinks he's helping but he actually puts me off'...

or:

'...sometimes for example, people at work say I could do it if I prioritised it, that pisses me off, they're not me, how would they know'...

Another woman's account was of a partner who did not support her taking time to exercise, though he suggested she should do so at some point. In addition, there was at least one woman who did not receive any encouragement and another who felt her partner wanted to be encouraging (and suggested they exercise together) but because they had such different abilities, he was not very patient.

Social support for physical activity is widely studied and research has consistently confirmed that women want encouragement and support for physical activity from the important people in their lives, - that is significant others, family and friends. ${ }^{132}$ Although the amounts and types of social support received by the women in the groups varied, according to Henderson (2003) the majority of women who undertake physical activity find empowerment through social networks. ${ }^{133}$ Many studies have found a positive association with social support and physical activity. ${ }^{134}$ At least some studies acknowledge the part the employer, for example, may play in providing opportunities to fit physical activity into the working day. ${ }^{135}$ However, the

\footnotetext{
${ }^{132}$ Dacey, Baltzell, and Zaichkowsky, "Factors in Women's Maintenance of Vigorous or Moderate Physical Activity.", Karla A. Henderson, "Enhancing Women's Physical Activity Involvement," Women in Sport \& Physical Activity Journal 7, no. 1 (1998), Segar et al., "Fitting Fitness into Women's Lives: Effects of a Gender-Tailored Physical Activity Intervention."

${ }^{133}$ Henderson, "Women, Physical Activity, and Leisure: Jeopardy or Wheel of Fortune?."

${ }^{134}$ Allender Steven, Cowburn Gill, and Charlie, "Understanding Participation in Sport and Physical Activity among Children and Adults: A Review of Qualitative Studies.", Maya A. Skowron, Monika Stodolska, and Kimberly J. Shinew, "Determinants of Leisure Time Physical Activity Participation among Latina Women," Leisure Studies 30 (2008).

${ }^{135}$ Rachel A. Prosser, Anne C. Thomas, and Cynthia S. Darling-Fisher, "Physical Activity Intervention in an Academic Setting: Focus Group Results," American Association of Occupational Health Nurses Journal 55, no. 11 (2007), Tavares and Plotnikoff, "Not Enough Time? Individual and Environmental
} 
complexity of social relationships should be noted here, as the social networks that can facilitate physical activity for the women, are the same networks and relationships that can create barriers to opportunities for their physical activity. ${ }^{136}$ Furthermore, social support need not be defined solely in terms of providing support for motivation.

\section{Physical environment factors that influence physical activity}

Physical environment factors expressed as barriers did not figure prominently in comments by the women in the focus groups. However, there were instances of wanting a:

'...change of scene...being out in the environment'... (Rhonda)

and:

'...wanting a nice environment'... (Annabel),

this in reference to not wanting to walk in the industrial area where Annabel worked, as well as not wanting to ride the wind trainer in the garage, for example (convenience was not enough). There were mentions of physical features like hills, weather, rain, wind and cold and with seasonal associations like daylight savings and darkness:

'...ah there's one other thing and that's daylight (yeah, yeah) daylight is a factor (yeah true) it's much easier in the summer... (hmm, hmm) (Sandra) easier in the summer as less gear and clothes to deal with... (Karen, married, works full time, no children at home)

longer days and less schedules to deal with'... (Donna).

\section{Barriers to opportunities for physical activity:}

As was noted in the discussion on personal factors that influence physical activity, most of the women were not getting to do much physical activity right now, other than walking. There were occurrences of attending classes or sessions once a week and one woman walked to work:

Implications for Workplace Physical Activity Programming among Women with and without Young Children.", Henderson, "Enhancing Women's Physical Activity Involvement."

${ }^{136}$ Eyler et al., "Correlates of Physical Activity among Women from Diverse Racial/Ethnic Groups." 
'...twice a week, but then I've traded off my morning for tonight (to attend focus group) and I don't think I should walk home, though I did bring my walking shoes'...(Sandra).

Two women did state they walked most days, but they were the exception.

This is supported by the most recent research from SPARC (2008), whereby 'during any week $79 \%$ of adults participated in at least one sport or recreation activity'. However, as SPARC noted:

the percentage who participated in at least one sport or recreation activity decreased as the timeframe shortened (i.e. year, month, week), ${ }^{137}$

and when measured against the number of adult New Zealanders achieving the guidelines the numbers drop significantly to $48.2 \%$. $^{138}$

Nearly one third of participants indicated they were more active now even though they felt they would still be outside the guidelines $(55.6 \%$ of all women in New Zealand are outside the physical activity guidelines). ${ }^{139}$ Many of these women were more physically active than they used to be, mainly in response to various health concerns that could be counteracted with physical activity (for example knee injury, spinal condition, cholesterol):

'...I have a problem with my knee, if I stop being active, I feel the pain come back. I used to go to the gym but I found it too time consuming, so now I walk every day'... (Patricia).

Friends motivated one woman: '... and I thought bugger it if they can do it I can do it' (Glennys, single, no children)... and has her first triathlon to work towards as a goal.

However, the majority of the women were less active now for a variety of reasons, many related to time to do with having a family and working:

'...being a mother and having a lot more commitments...

and being tired yeah, constantly tired...

no time's the big thing, especially with three kids...

\footnotetext{
${ }^{137}$ Sport and Recreation New Zealand. "Sport, Recreation and Physical Activity Participation among New Zealand Adults: Key Results of the 2007/08 Active New Zealand Survey." (Place Published. ${ }^{138}$ Ibid. (Place Published.

${ }^{139}$ Ibid. (Place Published.
} 
we [women] sort out the chaos of family life...

as [other participant] said earlier, women have that tendency to put everyone ahead of themselves...

too many balls in the air...there's always that balancing act you're sort of playing at'...

Issues to do with time mainly to do with family roles and caring were by far the most frequently mentioned barriers. Also included were comments to do with 'planning it and fitting it in', routinisation, 'takes too much time' (daylight and seasonal comments associated with the time of day, or year, such as that it's easier in the summer, or school holidays) and being too busy or having too much to do:

'...but um, one issue I have is that my husband travels a lot with work so he can come home at night and say 'look I'm off to Auckland for a couple of nights', so anything I've got planned does get put aside'... 'so yeah, you do what you can'... (hmm hmm) (Absolutely)... (Frances, married with two children).

Or:

'...during school terms there's no time... by the time I get home and sort the kids out, discover what the arguments about and solve it (hmm hmm hmm) sort the father out and get them all off to bed by 9:30 ...it's sort of well, it's my time now I think I'll just (group laughing) curl up on the chair with a book and a glass of wine'... (Donna).

There are a multitude of issues, from a number of sources, which influence time and serve to illustrate the demands on the women. First, issues of women and time are well researched in a number of capacities to do with managing multiple roles in relation to work ${ }^{140}$, family ${ }^{141}$, or personal attributes. ${ }^{142}$ Second, time is expressed in

\footnotetext{
${ }^{140}$ Prosser, Thomas, and Darling-Fisher, "Physical Activity Intervention in an Academic Setting: Focus Group Results.", Tavares and Plotnikoff, "Not Enough Time? Individual and Environmental Implications for Workplace Physical Activity Programming among Women with and without Young Children."

${ }^{141}$ Nomaguchi and Bianchi, "Exercise Time: Gender Differences in the Effects of Marriage, Parenthood, and Employment.", Wendy J. Brown and Stewart G. Trost, "Life Transitions and Changing Physical Activity Patterns in Young Women," American Journal of Preventive Medicine 25, no. 2 (2003), Amy E. Eyler et al., "Physical Activity and Minority Women: A Qualitative Study," Health Education \& Behaviour 25, no. 5 (1998), Skowron, Stodolska, and Shinew, "Determinants of Leisure Time Physical Activity Participation among Latina Women."
} 
terms of the 'right time' outside other demands. For example, when queried, the women responded with a variety of answers to do with 'when and how' they prefer to be physically active. There was also some discussion around 'the right time', and even the 'right activity'. Not only did this encompass finding the time in the first instance, it also had to be at the right time of the day. Some did not like doing things in the evenings, while others preferred the evening ... 'I just can't cope with the 6:00am thing anymore' ... but felt that it was even less likely to happen at that later time of the day due to caring commitments. While there were others who felt that if it did not happen during the day, most likely during work hours or lunch times, then it was unlikely to happen after that, again mainly due to childcare and household commitments:

'...after school you've basically got all of their activities and getting them to bed and whatever by sort of like 7:30 and then you're really too late to be doing stuff'...

Exercise at the end of the day seemed logical, 'but I'm so tired'. Comments directed at getting up early, and whether or not you tended to be a morning person or an evening person, ('larks and owls') were recognized as having their respective drawbacks in relation to being tired.

Generally, when considering physical activity, work commitments were supplementary to the time issues:

...'Well and then work which is time,... uhm so it's whether you can take the time out of work 'cause that's often the problem'...(Betty, married, no children living at home, works full time)

and work pressures, such as actually being able to get away from your desk. This issue is raised in another manner whereby you also needed to be in the position at work to be able to leave:

... 'that (comment) reminds me of an old fellow I know who made a point to walk to meetings...but he said he had that privilege because he was at the top

\footnotetext{
${ }^{142}$ Henderson and Bialeschki, "Inclusive Physical Activity Programming for Girls and Women.", Henderson, "Women, Physical Activity, and Leisure: Jeopardy or Wheel of Fortune?.", Im et al., "Midlife Women's Attitudes toward Physical Activity."
} 
of the company so he could do that, he realised others didn't have that time'..(Isabel).

Other work related affects had to do with guilt about leaving work to exercise, and for some, time at work directly reflected earning potential as they charged out by the hour, and were paid for the time they were there. Work was demanding and was a significant factor in affecting energy levels. In addition, work does not simply refer to paid work, as often after work, many of the women still had housework to contend with as well as managing partners and children. Housework was time consuming and physically demanding and cut down on the time and energy to be able to take part in physical activity. ${ }^{143}$

Motivational - type responses that emerged from the discussions around barriers were associated with the idea of convenience:

'...you just can't do anything'

and that it has to be something you like:

'...something that spins your wheels'

or:

'...finding your niche'...

or you:

'...won't make the effort'.

This is strengthened with references to exercycles and wind trainers again in terms of convenience such as having them at home:

'...but the old boredom factor is quick to set in'.

Some women also mentioned the idea of 'lack of partner' or as needing someone to 'go with' as a motivating factor to get themselves out the door:

'...you're right I think doing it on you own...it's just, it's lonely'...

'... and when you go do it with someone else you've got a commitment'...

However, the presence of other people was expressed in another way as well.

Wanting or having one other to do things with as a motivating factor was mentioned, but also being in an area where there were others around was also mentioned as a

\footnotetext{
${ }^{143}$ Skowron, Stodolska, and Shinew, "Determinants of Leisure Time Physical Activity Participation among Latina Women."
} 
feature that could 'put you off.' For one woman, exercising or taking part in physical activity in the presence of others was too embarrassing:

'...I feel self-conscious, so I don't want to go [to the gym] it makes me feel fat and unfit'...

Concern with image influenced a number of barriers. From a practical point of view, there was a distinct disadvantage for example of 'arriving somewhere smelly', pointed out in reference to incorporating physical activity on the way to work. Walking was used as an example and the discomfort associated with:

Madelyn: '...arriving dripping sweat and red-faced...you get self-conscious turning up like that'...

Julia: '...It's not a good look being all red in the corporate environment when you have to portray a certain image'...

An additional concern had to do with the logistics around what you needed as part of an exercise regime, such as clothing and hair dryers for example, and how you carried them.

Child-care issues, though generally not a concern amongst women of this demographic, was raised in some instances as a barrier:

'...whether or not you can afford extra childcare, or if you have a supportive partner'... (Olinda, married, three children, works part time).

This comment was in reference to having to potentially pay someone to look after the children, as there was not any family or friendship support available otherwise. There were a number of instances of this, as some of the women who participated in the groups were not from New Zealand originally and did not have family support to help out. Some of the women parented alone, for example, and did not have a current partner (and in one case, any family at all) to help with child minding. This introduces the idea of the 'value' of physical activity, as one woman spoke to me independently about how she joined the Board of Trustees at the children's school to get out in the evenings (as did another woman). Her husband saw this as an acceptable way to spend time so would look after the children for her to be able to attend meetings. However, he balked at the idea of looking after the children for her to fit in some exercise or physical activity. This fed into a general feeling that 
physical activity was not important enough to warrant having to pay someone so that one could take part, and in the above example, it was not important enough to be away from the home for, even when the partner was available to provide the childcare.

At least one of the women stated that even when she took her children to the pool, she feels guilty swimming 'lanes' instead of playing with them. Her choices are that either she swims lanes and feels guilty or, she plays and does not get any exercise for herself. Her solution is to do neither, so she sits at the sidelines and watches. Sitting on the sidelines was a theme raised several times:

'...we become spectators at our children's sports'...

'...Yes you spend a lot of time driving and taking the kids to their sport but not doing any yourself'...

Queenie: '...Yeah and I was doing that [hot yoga] and it's always on Saturday mornings, early, and then the kids' schedules sort of like and then I stopped doing it. So I always put the kids first, that's the problem, you know so it's like if their sport comes up and takes priority then that takes priority'...

Rhonda: '...I used to get out on an early morning bike ride or run or something on a Saturday, but then Saturday sport has come and it's funny cause like it's almost like virtual sport I mean, I used to play (laughs, yea) hockey myself and I really enjoyed going and watching my kids games and I'm sure I'm getting this like virtual benefit from (group laughing) mentally playing'....

For a more comprehensive discussion of 'how women clear space for and directly contribute to the leisure of others' see Shona Thompson, 'Women and Leisure in Aotearoa/New Zealand and Australia' in Perkins and Cushman's (eds) 'Time out? Leisure, Recreation and Tourism in New Zealand and Australia (1998). ${ }^{144}$

\footnotetext{
${ }^{144}$ Shona Thompson, "Woman and Leisure in Aotearoa/New Zealand and Australia," in Time Out? Leisure, Recreation and Tourism in New Zealand and Australia, ed. G Cushman and Harvey C. Perkins (Auckland: Addison Wesley Longman, 1998).
} 
The following response (See Figure 4 below) is one woman's keen reflection of the focus group discussion. It is a good example of the typical kinds of barriers and constraints that women may face over a life course. This reflection is from Isabel; she works part time, and is married. She has five children (one set of twins) four of whom are at school and one aged over eighteen. Isabel comes from a very active background and used to be an avid sportswoman. 
Figure 4: Isabel's reflection

\section{Women and Physical Activity Focus Group: Isabel's reflection.}

...You said how most women say that they are too tired or busy to participate. We discussed that, as needing to attend to too many people's needs or draws on our time, eg. family, pets, household duties, maintaining relationships plus or minus work, most women are exhausted at the end of the day and just don't want to contemplate yet another activity. An extension of that is how we are active in our daily lives over time. (life cycle stuff):

At school, most Kiwi women said that they participated in and enjoyed the structured physical activities until school ended, or a girl decided it wasn't feminine to play hard. Next, she is establishing a career and/ or finding a mate, neither of which suggests a lot of sweating, and sets up feminine dress habits. Then comes pregnancy, which tends to slow most women down somewhat, while society tells us we should be careful with our bodies (ie-don't get hit by a volleyball, or compromise the guy's pleasure of the activity by needing to be aware of delicate female concerns ). Birth and breastfeeding takes its toll physically, then there's years of carrying around a baby (not good on the field. Even the jogging buggies are available only to the 'rich' and jogging types). One learns to slow down to the toddler's pace. Young children's games are usually within an easy range of adult physical skills, so there's no aerobic push there. So, there's little opportunity to keep up high levels of physical fitness in day to day living. We then become spectators at our children's sports. Suddenly, the children walk faster and play harder than their mom. She finds herself at the end of the walking file, no longer because the weakest link needs her help and encouragement, but because she is now the 'weakest link'. How is her physical self-confidence? (NB I haven't even added in the JOB factor)

Now, a woman might be contemplating a return to 'exercise', but finds that her body has aged, her endurance level has dropped, her general speed has decreased, her time availability is still limited, AND where does she find people and activities that match her current skill base????? It can be TOO HARD. The incentive to be active when you are 'old', unfit, uncool, slower than your loved ones, and possibly compromised by injury, is mighty low! No wonder just the thought is exhausting enough to put one off. 
Multiple social roles and the expectations that are placed on women continue to influence and hinder their opportunities for physical activity. These women are highly committed to caring roles, leaving little or no time for themselves, or there is an increased incidence of choosing everyone and everything ahead of themselves and constantly putting their own needs last. This concept is known throughout the literature as the 'ethic of care'. ${ }^{145}$

Gilligan's 'ethic of care' is best viewed through a context of relationships, ${ }^{146}$ and is considered an integral component of women's moral reasoning that is bound up in conceptions of self, relationship and responsibility. ${ }^{147}$ It is characterised not necessarily by gender, but by theme or a 'care perspective' defined by care and responsibility and response. ${ }^{148}$ A care orientation is inherent in a sensitivity to the needs of others and the assumption of the responsibility for taking care. It is best summarised as the orientation of women to relationships involving care and tending to the needs of others.

According to Nomaguchi and Bianchi (2004), women tend to give priority to work and family responsibilities ahead of themselves and their leisure time, creating role strain. Role strain dictates that demands from work and family roles often compete with individual needs, and that there is an inherent difficulty in fulfilling role obligations and individual needs. Individuals allocate their time based on the priority they place on each of their social roles and there is interconnectedness in role obligations and choosing time for oneself. According to Nomaguchi, this is compounded when the leisure activity of choice is physical activity. ${ }^{149}$

Lewis and Ridge (2005) elucidate this further when they state that although women are aware of the importance of caring for themselves, there is a maternal 'ethic of care' that can make it difficult for women to prioritise time for self over their child rearing and domestic responsibilities. They relate this to a cultural notion of the

\footnotetext{
${ }^{145}$ Gilligan, "Moral Orientation and Moral Development."

${ }^{146}$ Ibid.

${ }^{147}$ Margaret Urban Walker, "What Does the Different Voice Say?: Gilligan's Women and Moral Philosophy," The Journal of Value Inquiry 23 (1989).

${ }^{148}$ Ibid.

${ }^{149}$ Nomaguchi and Bianchi, "Exercise Time: Gender Differences in the Effects of Marriage, Parenthood, and Employment."
} 
'good' mother and regard this to be an underlying notion and central theme underpinning women's decision-making around physical activity. ${ }^{150}$ This is consistent with Miller and Brown (2005), who found that taking time out meant the women were avoiding their responsibilities. ${ }^{151}$ Moreover, according to Henderson, women may even feel uncomfortable or guilty about taking time to spend on individual leisure pursuits including physical activity. ${ }^{152}$

Leisure activities can be characterised as formal or informal. ${ }^{153}$ Formal leisure activities are those that are often scheduled as a regular activity, such as choir or a language class for example, and have times that are set aside purposefully for the activity. Informal leisure is less structured and does not have a scheduled time element to it. Physical activity is often less mandatory than formal leisure activities, and does not often come with such a regular schedule (unless you participate in a class) and is generally left to the individual to set and monitor their own schedules. Nomaguchi states it is much more difficult to combine physical activity with other activities related to role demands, as physical activity often requires focused energy and may not be easily combined with other activities or child minding. To participate in physical activity, there needs to be a certain amount of flexibility and relative freedom from other demands. Therefore, when there is a clash of schedules or timing with regards to family or work responsibilities, it is easier to defer the physical activity whereas there might be more reluctance to miss the scheduled time of choir or a music lesson for example. This Nomaguchi states only adds to the demands of setting aside time for physical activity. ${ }^{154}$

Some leisure activities are more serendipitous than others, whereby an opportunity may present itself (television watching or reading for example) whereas physical activity generally takes some planning and is less 'likely to drop into your lap'.

\footnotetext{
${ }^{150}$ Lewis and Ridge, "Mothers Reframing Physical Activity: Family Oriented Politicism, Transgression and Contested Expertise in Australia."

${ }^{151}$ Miller and Brown, "Determinants of Active Leisure for Women with Young Children - An "Ethic of Care" Prevails."

${ }^{152}$ Henderson, "Women, Physical Activity, and Leisure: Jeopardy or Wheel of Fortune?.", Lewis and

Ridge, "Mothers Reframing Physical Activity: Family Oriented Politicism, Transgression and

Contested Expertise in Australia."

${ }^{153}$ Nomaguchi and Bianchi, "Exercise Time: Gender Differences in the Effects of Marriage,

Parenthood, and Employment."

154 Ibid.
} 
Physical activity can be categorised as formal, particularly as it does for some of the women, if one belongs to a class that is held or meets on a regular basis. But for most, physical activity appears to be more of a 'catch as catch can' process, where if there is a demand on one's time or a conflict in multiple roles, then physical activity is the thing that can be readily discarded or deferred.

For many of the women, this situation arises mainly with regards to their roles and duties as parents and caregivers 'coming first'. This is consistently affirmed in the research, as many have acknowledged a strong 'ethic of care' still present in the women's relationships, parenting and care giving duties. ${ }^{155}$ There are several issues bound up in an 'ethic of care', as women, regardless of race or ethnicity, perceive child-care and household responsibilities as significantly affecting their access to physical activity. ${ }^{156}$ Of interest here is that it is also present in the relationships of the women without any children as well. Some of the women have children who have grown up and left home and as such, the 'ethic of care' may be an engrained habit from a previous time, but at least one other did not have children. Those women appear to run the households and be responsible for a greater amount of the housework, even though they also work full time. The house and home remains the domain of women it seems, whether they are in the public world or not.

For some women, it is a case of managing too much of everything,- jobs, children's school, housework-, and, when it presents itself, some free time as well, though in some cases the women said they used time free of the children to run errands or perform chores. The 'ethic of care' seems to be present in all aspects of the women's lives as a long list of things to do. Physical activity, when it happens, becomes a managed task or chore that is added to the long list, and generally at the bottom of

\footnotetext{
${ }^{155}$ Shaw, "Conceptualizing Resistance: Women's Leisure as Political Practice.", Henderson, "Women, Physical Activity, and Leisure: Jeopardy or Wheel of Fortune?.", Lewis and Ridge, "Mothers Reframing Physical Activity: Family Oriented Politicism, Transgression and Contested Expertise in Australia.", Skowron, Stodolska, and Shinew, "Determinants of Leisure Time Physical Activity Participation among Latina Women.", Nomaguchi and Bianchi, "Exercise Time: Gender Differences in the Effects of Marriage, Parenthood, and Employment.", Miller and Brown, "Determinants of Active Leisure for Women with Young Children - An "Ethic of Care" Prevails."

${ }^{156}$ Miller and Brown, "Determinants of Active Leisure for Women with Young Children - An "Ethic of Care" Prevails.", Skowron, Stodolska, and Shinew, "Determinants of Leisure Time Physical Activity Participation among Latina Women."
} 
that list and in this manner ceases to be leisure in any way. This is what Godbey (cited in Haworth) refers to when he describes the concept of anti-leisure: ... activity, which is undertaken compulsively, as a means to an end, from a perception of necessity, with a high degree of externally imposed constraints, with considerable anxiety, with a high degree of time consciousness and a minimum of personal autonomy $(p 4) .{ }^{157}$

This raises the issues of the women taking time for themselves and breaking out of the stereotypical roles of housewife and mother. Taking time for themselves seems to be an issue for many of the women, especially in the light of the myriad of other demands and duties that make up their days. However, when time was taken out for physical activity, the perceived benefits in doing so were widely acknowledged:

'... It gives that sense of well being. When I'm focused and committed in my head, I feel better

...I sleep better; I find it helps me wind down

...It gives me a sense of 'my time' and 'my space' - which also gives me selfconfidence and is better for me in the long term

...It gives me more energy in the day

....agrees ... makes her feel great'...

The benefits associated with taking time out for physical activity, like developing better coping skills, for example would be justification visible for doing so. Lewis and Ridge (2005) reiterate this in their research on mothers with young children and their access to physical activity. They state that the benefits for women (and subsequently their interrelations), of taking some time for themselves would more than justify their reasons for choosing to take time outside their family and care giving duties ${ }^{158}$

Clearly, the women find it difficult to take time out when there is work to be done such as being with the children, helping with the homework, doing the laundry. This lack of a sense of entitlement appears to be unique to women as a factor in the "ethic of care' as Miller and Brown (2005) find that men are more likely to give precedence

\footnotetext{
${ }^{157}$ John T. Haworth, Work, Leisure and Well-Being (London: Routledge, 1997).

${ }^{158}$ Lewis and Ridge, "Mothers Reframing Physical Activity: Family Oriented Politicism, Transgression and Contested Expertise in Australia."
} 
to personal leisure over domestic responsibilities. ${ }^{159}$ This was certainly confirmed by women in my study with comments like:

'...I dunno if it's just the guilt thing with women where he will take 'me time' (oh yes) for running and cycling and stuff like that and say I'm going to go off for a bike ride for an hour and a half on the weekend or whatever and he feels no guilt about it whatsoever. But, if I said it, he would probably say well what am I going to do with the kids?'... (hmm, hmm)

'...In the meantime he will have watched a whole TV programme (yep) and... he says oh I'm off to bed, hmm not every night but enough that you kind of think now why don't I do that? And it's quite amazing... and I agree with him, he does a huge amount ...but they still have an ability to create time and to sit'...

Or:

'...As (other participant) said earlier, women have that tendency to put everyone ahead of themselves'...

'...Yeah, we sort out the chaos of family life, men just do their own thing they don't notice all the little things we do that take up time... Why can't they do it?!'...

The women in my study were highly committed in their multiple roles to be able to make the time for physical activity with any regularity. Too many demands on time associated with work and family life are the main 'culprits' that keep women from being physically active. This underlying 'ethic of care' is exacerbated by and connected to perceived societal notions of being a 'good' wife and mother. The 'ethic of care' and family responsibilities contribute widely to the women's [in]abilities to make time for themselves. In addition, some women feel guilty for spending time doing something for themselves outside their roles of mothers and carers. Time for themselves, and subsequently physical activity, is relegated to the bottom of a long list dictated by a hierarchy of demands where her needs come last. 160

\footnotetext{
${ }^{159}$ Miller and Brown, "Determinants of Active Leisure for Women with Young Children - An "Ethic of Care" Prevails."

160 Ibid.
} 


\section{Summary}

In this chapter, I have presented the sample characteristics and provided a short profile of each of the women who participated in the focus group discussions. I began the findings with a discussion on their perceptions of physical activity; what physical activity meant to them; and how this is articulated. I then outlined and discussed the findings in relation to the major themes from the ecological model with a further section on barriers to opportunities to physical activity. The discussion points are interspersed with relevant sections of the conversation, which best illustrate what the women were saying, and were then linked back to relevant literature to support the claims being made. A summary of the main findings and implications from the chapter are discussed in the final chapter on conclusions and direction. 


\section{CONCLUSIONS AND DIRECTION}

The women in this study were chosen purposively to fit the demographic of the survey group in the original SPARC (2006) study. Recruiting was devised specifically around children, for example through school newsletters, or around paid work situations, and I went looking for the busiest women I could find. The purpose of the research was to explore the barriers for women to have opportunities for physical activity. The findings of the group discussions were in keeping with ecological theory, suggesting that multiple factors influence the women's opportunities for physical activity. However, personal and social influences were more prominent than features of the physical environment in terms of affecting opportunities for physical activity.

Social environment factors that support and influence opportunities for physical activity (e.g. family, paid/unpaid work), indicated the women want encouragement and support for physical activity from important people in their lives such as family, partners and friends. Social aspects also included the role of work or the employer in physical activity, planning and routine, effort, and the reality of busy lives.

Barriers to opportunities for physical activity in the social domain were those mainly to do with family roles and caring, as well as participation in paid and unpaid work and managing multiple roles.

Exploring motivation - intrinsic and extrinsic - and personal factors such as attitudes, meaning and perceived benefits of physical activity, yielded a number of key themes. Generally, the women had positive attitudes to physical activity and physical activity was undertaken for a number of benefits, for example, health/well-being, weightcontrol, body image, fun, enjoyment and the social aspect in participating with others. Also included was the idea of 'time out', or 'me time' associated with physical activity as a way of relaxing, re-energising and de-stressing. Ultimately, the women appear to choose to be physically active because they want to be and for the most part like to be physically active and enjoy physical activity. Motivational type barriers were situated around the ideas of convenience ( 'you just can't do anything'), lack of partner, concern with image and logistics around what you needed to organise (clothes, hairdryers, toiletries), and sometimes how you carried that. Other barriers 
had to do with child-care issues and tiredness, and little time for themselves associated with managing multiple (caring) roles.

In considering current behaviour and patterns of physical activity, how these change and in what context, the majority of the women reported they were less active now for a variety of reasons, mainly in the context of the demands on their time. Time was allocated based on the priority they place on each of their social roles and there was little time left over for choosing leisure time activities or time for themselves. While many of the women participated in some physical activity, they would still fall short of the national guidelines, and barriers were mainly expressed as access to opportunities often dictated by the demands and commitments associated with their social roles.

This thesis has been concerned with understanding the ways in which women in this "demographic" have access to opportunities for physical activity and a central feature of the thesis has been the reality of busy lives. This has translated into a comprehensive examination of the factors affecting women's decision-making around physical activity, and how they participate, which takes into consideration what they have to say about their physical activity experiences within the totality of their lives. ${ }^{161}$ As much of physical activity research is conducted from a health outlook, a goal of the research was to explore the research problem from a more social perspective. Social constructionism and an emphasis on the primacy of relationships have underpinned the research process. In addition, I utilised feminism and ecological theory specifically to explore a range of settings that influence decisions made around physical activity. Ecological theory is unique in that it takes into consideration the principle of interconnectedness that applies not only within settings, but also with equal influence between, or across settings. Nothing is considered in isolation. ${ }^{162}$ Feminism allows for a widening scope of women's meanings and experiences of physical activity and opportunities for physical activity outside a typical health model. It informs and allows for an exploration of women's physical activity decisions, within a social context, that draws on and connects with their

\footnotetext{
${ }^{161}$ Vertinsky, "Run Jane, Run: Central Tensions in the Current Debate About Enhancing Women's Health through Exercise."

162 Bronfenbrenner, Making Human Beings Human: Bioecological Perspectives on Human Development.
} 
experiences as women, mothers, caregivers and partners. I used focus groups to explore the topic amongst small groups of women gathered together expressly for that purpose; to discuss the barriers to opportunities for physical activity.

However, there are some limitations associated with the study that need to be taken into consideration. This study has taken place in a particular place and time, and as such can only be regarded in that context. It is essentially a study based on middleaged European New Zealand women leading very busy lives, and it is seen from the point of view of a woman researcher who fits this description as well. It is important to recognise that this research did not address a full range of barriers to being physically active encountered by, for example, economically disadvantaged and marginalized women. ${ }^{163}$ In the study, women of lower education were not represented, and there was only one ethnic minority participant in a sample of nineteen. Because of this, economic, or ethnic-specific or cultural factors that might influence some women's access to opportunities for physical activity were not explored, and hence the findings cannot be generalised outside the particular demographic. I acknowledge that these experiences may well not cover a full range of possibilities, and that women of different ethnic groups and socio-economic status are likely to face barriers at both the individual and social levels, distinct from those identified in this study. Another possible limitation is sample bias. Women who volunteered to participate in the focus groups may be self-selected for their interest in physical activity, their activity levels, and for their positive perceptions about physical activity.

These observations suggest a need for more research into the physical activity patterns of certain groups of women and there is considerable scope for subdividing the group 'women'. As the wider group involves many different categories of women, a qualitative evaluation that focuses on the experiences of women in different sub-groups may be insightful. For example, further studies with a larger number of ethnicities are needed to understand the specific barriers to their opportunities for physical activity in the context of their lived experiences.

\footnotetext{
${ }^{163}$ Segar et al., "Fitting Fitness into Women's Lives: Effects of a Gender-Tailored Physical Activity Intervention."
} 
The focus groups results yielded a strong 'ethic of care' amongst many of the women who participated in the groups. The 'ethic of care' as theorised by Gilligan (1982), is enduring as the women portray a responsibility to a care perspective and a sensitivity to the needs of others whereby their needs come last. ${ }^{164}$ Furthermore, as cultural and societal expectations are slow to change, the type of emotion work involved in caring still falls mainly to women, and women still seem largely responsible for managing the children, the family and the household. This affects how women spend their time or access to time, and the kinds of experiences they have as a result of being constrained in that manner. This often results in a reduced quality in or of physical activity. The 'ethic of care' is well supported in the literature from many disciplines such as feminism, gender studies, psychology, leisure studies and health. In addition to the 'ethic of care', and caring for others, the responsibilities of work or study result in a constant demand on time, and time was a major factor involved in the women managing their various social roles. The presence of children in the home as a factor affecting access to opportunities for physical activity for many of the women was apparent.

The research also established that many of the women had an attitude to physical activity that is suggestive of leisure time and a notion of enjoyment. Enjoyment is important, as previous research has confirmed that enjoyment is a key factor that determined whether women are likely to participate in physical activity. ${ }^{165}$ That is, my participants undertook physical activity mainly because it was something they liked to do, as a way of spending time on themselves and as a means of selfexpression. This attitude to physical activity resulted in a general disregard of incidental activity which in total count for 30 minutes a day or more. There was the idea that incidental physical activity could have a functional element to it that could be equated to the obligatory nature found in 'physical activity for health' messages. Both were seen as having a compulsory element, and take on a quality known as antileisure. Anti-leisure is what Godbey (cited in Haworth) refers to when he describes activity that is a means to an end, with a high degree of externally imposed

\footnotetext{
${ }^{164}$ Carol Gilligan, In a Different Voice (Cambridge: Harvard University Press, 1982).

${ }^{165}$ Henderson, "Women, Physical Activity, and Leisure: Jeopardy or Wheel of Fortune?."
} 
constraints, with considerable anxiety, time consciousness, and containing a minimum of personal autonomy. ${ }^{166}$

Domestic exercise denies women a right to claim their own time for physical activity and self-expression and in doing so also denies the underpinnings of societal stereotypes that continue to reinforce this. There is a contradiction involved in giving domestic obligations an activity credit, suggesting that this take the place of what might otherwise be physical activity expressed as leisure. Furthermore, leisure involving family more commonly involves work for women and mothers in two ways. In the first instance, there is work (housework) that most likely needs to be accomplished ahead of any leisure, thereby fulfilling properly the cultural roles of wife and mother. Secondly, work in organising and supporting family activities also inevitably falls to women in their roles of 'good wife' and particularly 'good mother'. ${ }^{167}$

This of course opens up the potential for a myriad of research opportunities. As was suggested earlier, there is the possibility for stratifying the sample, for example based on age, ethnicity, income, partnered relationship status or sexual orientation. In particular, it is worthwhile investigating the impact of life stages of women and their opportunities for physical activity, as well as the influence of the number and ages of children in the household. There is a diverse range of research opportunities that can be explored along the lines of the notion of gender and its various social effects. Also worthwhile would be to undertake a comparative study of men's and women's access to free time and leisure. In their most recent study on measuring leisure, the Organisation for Economic Cooperation and Development (OECD) found that New Zealand is now one of only three OECD countries where women have more 'broad leisure ${ }^{168}$ time than men. They qualify their use of the term 'broad leisure' as including daily and gender-specific levels of personal care. ${ }^{169}$ It would be useful to explore the definitions and meanings of leisure time in that context. Although my

\footnotetext{
${ }^{166}$ Haworth, Work, Leisure and Well-Being.

${ }^{167}$ Lewis and Ridge, "Mothers Reframing Physical Activity: Family Oriented Politicism, Transgression and Contested Expertise in Australia.", Miller and Brown, "Determinants of Active Leisure for Women with Young Children - An "Ethic of Care" Prevails."

${ }_{168}$ Organisation for Economic Development and Cooperation OECD, "Special Focus: Measuring Leisure in O.E.C.D Countries," in Society at a Glance: OECD Social Indicators (2009). ${ }^{169}$ Ibid.
} 
focus is on women and their access to opportunities, for various reasons this is not to dismiss further qualitative explorations of physical activity outside the health context. There are good examples of this kind of research in New Zealand at present, such as Gidlow and Cushman's recent study that looks at the extent to which men who engage in the types of 'blokes' leisure - recreational hunting, diving and fishing negotiate their recreational space in consultation with significant others, notably their partners. ${ }^{170}$ A study that examines men's experience with gender stereotypes in physical activity may also be of further interest.

There is no one size fits all when it comes to physical activity. ${ }^{171}$ The health models rely too much on quantitative measures in which contextual features are treated as discrete variables to be overcome. Physical activity may be redefined as physical inactivity and is viewed as an individual problem. Intervention is viewed as treatment and solutions and is oriented towards the individual, with little consideration of personal context, or the influence of cultural values on behaviour. The casting of physical activity as primarily a health behaviour obscures a range of normal patterns of movement, and physical activity is devoid of context. ${ }^{172}$ Individuals are doing what they can and greater change needs to come from the wider society. Continual health messages in today's society are a common and regular occurrence. We are encouraged to be healthier and more active in a variety of ways to achieve a result or outcome. However, there are fewer messages which encourage participation in physical activity for the enjoyment of the experience and as a way to express ourselves.

My research suggests the need for a shift of focus away from the health models and theory towards a socio-cultural understanding of physical activity as enjoyable leisure time. Specifically, there needs to be more research on women and physical activity in the New Zealand context in an attempt to deconstruct and reconstruct several social norms around women's social roles. Women need to experience their physical self

\footnotetext{
${ }^{170}$ B. Gidlow and G Cushman, "Bringing Men Back In? Male Recreational Hunters, Divers and FlyFishers and the Creation of Recreational Space," Annals of Leisure Research 11, no. In press (2008).

${ }^{171}$ Karla A. Henderson, "One Size Doesn't Fit All: The Meaning of Women's Leisure," Journal of Leisure Research Summer (1996).

${ }^{172}$ Janet D. Allen, "A Biomedical and Feminist Perspective on Women's Experiences with Weight Management," Western Journal of Nursing Research 16, no. 5 (1994).
} 
outside the social constructs associated with body image, social roles and the corresponding behavioural expectations of those roles.

This research looks to go some way in redressing the imbalance between physical activity presented as a 'healthy behaviour' and physical activity as an enjoyable form of leisure time and self-expression. It may help demonstrate that physical activity needs to be re-cast. From a social sciences viewpoint, researching barriers to opportunities for physical activity for women contributes to a wider understanding and highlights the importance of how women experience physical activity in the context of their daily lives. In the meantime, and in the context of busy lives, this group of women will simply continue to 'do what they can'. 


\section{Appendix 1}

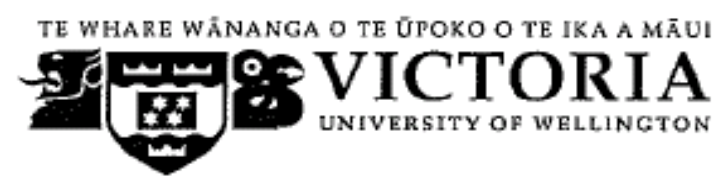

\section{THE TIME SQUEEZE RESEARCH PROJECT INFORMATION FOR PARTICIPANTS}

My name is Marilyn Northcott, and I am a post-graduate student at Victoria University of Wellington. I am doing research for a thesis entitled The Time Squeeze: Exploring the barriers to Women's Opportunities for Physical Activity for a M.A. (Applied) in Social Science research. This thesis will explore the link between various constraints and opportunities for women to participate in physical activity. I am interested in hearing about your experiences of everyday life and the possible contributing factors (such as working part/full time, family responsibilities) that keep you from having opportunities to participate regularly in physical activity.

The background information for this study is based on the Sport and Recreation New Zealand (SPARC) 2003 survey, Obstacles to Action: A study of New Zealanders physical activity and nutrition, in which a number of the target population identified themselves as 'too busy and too stressed' to participate in physical activity regularly. The most interesting feature of this group for me was of the respondents, $67 \%$ were women.

I am inviting women who do not participate in physical activity on a regular basis to take part in a focus group session in central Wellington (details to be provided). I will be holding three focus group sessions, and each group will be composed of around 8 women aged from $25-49$ years. The focus group evening is expected to be approximately two hours. Refreshments, tea and coffee will be provided, as well as a small gift for participating in the study.

As I do not want to miss any of your comments and conversation, I would like to tape record the discussion. I will also have a female research assistant, from the university, present to take notes so I can concentrate on the group discussions. The information that I gather will form the basis of my research, which will be written into my thesis.

All material collected will be kept confidential and no personal identifying information will be included. No other person besides myself and my supervisor, Dr. Lee Davidson will have access to the tapes and any notes taken. All tapes and other information collected as part of this project will be stored securely at Vietoria University, and destroyed two years after the end of the project. The thesis will be submitted for marking to the School of Humanities and Social Sciences and deposited in the University library. Should you have any questions, or if you would like to receive further information, about the project please contact me or my supervisor, Dr. Lee Davidson, phone: 04 463-5929.

If you would like to be a part of this study, then please consult the eligibility criteria on the back of this form. If you meet these requirements and wish to participate, please contact me via the details below.

If you do not meet the requirements, or do not wish to take part, please pass on this information to someone whom you think may like to do so. Many thanks for your time and consideration.

Kind regards

Marilyn Northcott

P: 044635032

M: 0275385885

E: marilyn,northcott@vuw.ac,nz 


\section{Focus Group Eligibility}

If you:

- $\quad$ are aged $25-49$

- do not take part in regular physical activity*

(i.e. less than 150 minutes -e.g. $5 \times 30$ mins, or 2.6 days per week)

are working in paid employment or study (full or part time)

"('Regular Physical Activity' means at least 15 minutes of vigorous activity -makes you huff and puffor

a total of 30 minutes or more of moderate activity -causes a slight but noticeable increase in breathing and heart rate- each day for 5 or more days each week. Include brisk walking.) 


\section{Appendix 2}

Dear Sir/Madam;

My name is Marilyn Northcott, and I am a post-graduate student at Victoria University of Wellington. I am doing research for a thesis entitled The Time Squeeze: Exploring the barriers to Women's Opportunities for Physical Activity for a M.A. (Applied) in Social Science research. This thesis will explore the link between various constraints and opportunities for women to participate in physical activity. I am interested in hearing about the experiences of everyday life and the possible contributing factors (such as working part/full time, family responsibilities) that keep women from having opportunities to participate regularly in physical activity.

I am contacting your school to ask if you would consider sending out this information to women in your school community via a central notice board, school newsletter, email newsletter or web-site, as I am wishing to get a wide distribution of the details of my study to ensure a good population to choose a sample from. For your convenience, I have attached the participant information sheet for distribution. Potential participants can respond directly to me via the contact details provided.

Should you have any questions or require any additional information, please feel free to contact me at this email address.

Many thanks for you time and consideration.

Kind regards

Marilyn Northcott

Research Student

M.A. (Applied)

Social Science Research (SSRE)

Victoria University of Wellington

Office: MY914

DDI: +64 44635032

Mobile: 0275385885

Email: marilyn.northcott@vuw.ac.nz 


\section{Appendix 3}

\section{Dear}

I just wanted to follow up and say thank you again for participating in the Focus Group last night. I found the evening to be very interesting, and quite enjoyable.

In addition to wanting to say thank you again, 1 also wanted to ask you if you would like to comment on what was the key thing you took away from the discussion, and if you have anything else you would like to add now?

Many thanks for your time.

Kind regards

Marilyn

Marilyn Northcott

Research Student

M.A. (Applied)

Social Science Research (SSRE)

Victoria University of Wellington

Office: MY914

DDI: +6444635032

Mobile: 0275385885

Email: marilyn.northcott@vuw.ac.nz 


\section{Appendix 4}

\section{Discussion Areas}

Physical Activity: Ok, we are here to talk about exploring the

barriers to women's opportunities for physical activity...

1. So, when you hear the term "physical activity," what do you think of?

- What does it mean to be physically active?

- What are some examples?

Use the prompts for "exercise" if it is mentioned:

- Do you think there is a difference between exercise and physical activity?

If there is a difference between "exercise" and "physical activity," probe to find out what difference is.

- If yes, what do you think the difference is?

"Exercise" is narrower in focus and is defined as "one type of physical activity conducted with the intent of developing physical fitness" (Corbin and Pangrazi, 1998).

If the group goes quiet:

- How about things like housework, gardening, physical labour on the job, home renovating, and such? Do you consider these to be exercise or physical activity?

- What is it about these particular activities that make them fit/not fit your idea of exercise?

2. What do you think are the advantages associated with physical activity for you?

Come back to this point to probe with:

If there is an 'elephant' in the room then introduce it:

Physical activity and health messages - 


\section{Appendix 4}

Prompts, if needed, to generate discussion include:

Outside or beyond the health message, what influences you to take part in physical activity?

- What makes this important for you?

- Do you get to do any?

- Why do you do it?

- How do you prefer to be physically active - on your own?

- With a group?

- With your family?

Note: Pick up on the ones that are not utility based- apart from achieving an end e.g. cleaning the car/cleaning the house.

3. What do you think are the disadvantages associated with physical activity for you?

4. How do you feel about physical activity?

- is it important to you?

- if yes, why is this so?

- if no, why not?

5. How important is being physically active to you?

- What makes you say that?

6. How much of a priority is it for you?

- Why do you say that?

7. What sort of physical activities are you involved in?

- this could be lots of answers.

- are you able to be involved in this activity now?

8. Thinking back, are you more or less active now than you used to be? 


\section{Appendix 4}

- if not as active now, what's changed?

\section{Visualisation statement:}

Think back to the last time you were regularly more physically active.

- What got you up and going, or out the door?

- What motivated you?

- Why were you doing it then?

Ask for specific suggestions:

- Who are the important people or groups that might have an influence on your physical activity?

Or

- How much encouragement do you get to be physically active?

- What are some things your family (spouse, children) could do that would be helpful?
a. What gets in the way of your being active?
b. What things make it difficult to be or stay active?
c. What makes it easier

9. To finish up then, do you see your situation changing in the next few years?

- Yes/No

- Why is this?

\section{WRAP UP}

( 5 minutes)

We've covered a lot of ground in the last two hours. Is there anything else you would like to tell me about trying to fit in Physical activity? Thank you 


\section{Appendix 5}

TE WHARE WÄNANGA O TE OPOKO O TE IKA A MĀU 59

\section{VICTORIA UNIVERSITY OF WELLINGTON CONSENT TO PARTICIPATION IN RESEARCH}

Title of project: The Time Squeeze

I have been given, and have understood, an explanation of this research project. I have had an opportunity to ask questions, and have them answered, to my satisfaction. I understand that I may withdraw myself (and any information I have provided) from this project at any stage, up to and including the analysis stage, and may do so by advising the researcher.

I understand that any information I provide will be kept confidential to the researcher and the supervisor. I understand the published results will not use my name, and that no opinions will be attributed to me in any way that will identify me. I understand all tapes and other information collected as part of this project will be stored securely at Victoria University, and destroyed two years after the end of the project.

- I undertake not to disclose to others, any personal information shared during the focus group discussions.

- I would like a summary of the results $\square$ Yes $\square$ No

If yes, please provide address details below

I agree to take part in this research:

Signature:

Date:

Full Name - printed:

Address details if applicable: 


\section{Demographic Questionnaire}

We appreciate your help with the following questions. Having demographic information about focus group participants will help us better understand the information we learn from the group discussions.

Please answer the following questions, ticking the check boxes that best represent your situation*:

Q 1. What is your age: (Please tick the one that describes you)

$\square 25-29$

$\square 30-34$

ㄱ 35-39

$\square$ प $40-44$

$\square$ 45-49

Q2. Which ethnic group do you belong to?

$\square$ New Zealand European

$\square$ Maori

$\square$ Samoan

$\square$ British/European

$\square$ Other, please specify:

Q 3. Are you ...

$\square$ Single

$\square$ Married/living with partner

$\square$ Separated/Divorced

$\square$ Widowed

$\square$ Other, please specify:

Q 4. Do you have any children (under the age of 18) currently living at home?

口Yes

$\square$ No

(If yes, how many and what are their ages?) 
Number of children living at home:

Ages:

Q 5. What is your highest education qualification?

$\square$ Secondary School qualification

$\square$ Some university/polytechnic

$\square$ University/Polytechnic degree

$\square$ Post Graduate study

$\square$ Other, please specify:

Q 6. Which one of the following best describes you?

$\square$ Working full-time in paid employment

$\square$ Working part-time in paid employment

$\square$ Student (full-time/part time)

$\square$ Other, please specify: 


\section{Appendix 7}

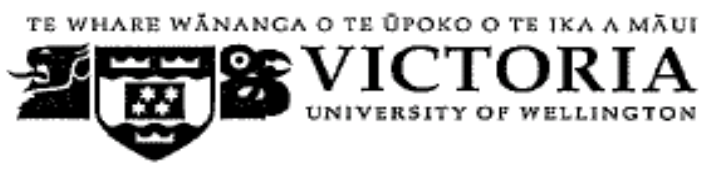

\section{CONFIDENTIALITY AGREEMENT}

The Time Squeeze - Exploring the barriers to women's opportunities for physical activity

$I$.

(Full Name - printed)

agree to keep confidential all information concerning the project

(Title of Project).

Signature:

Date:

Full Name - printed: 


\section{BIBLIOGRAPHY:}

Allen, Janet D. "A Biomedical and Feminist Perspective on Women's Experiences with Weight Management." Western Journal of Nursing Research 16, no. 5 (1994): 524-43.

Allender Steven, Cowburn Gill, and Foster Charlie. "Understanding Participation in Sport and Physical Activity among Children and Adults: A Review of Qualitative Studies." Health Education Research 21, no. 6 (2006): 826-35.

Anderson, Elizabeth "Feminist Epistemology and Philosophy of Science " In The Stanford Encyclopedia of Philosophy, edited by Edward N Zalta, 2009.

Australian Womensport and Recreation Association, AWRA. "About Time: Women in Sport and Recreation in Australia."

Ball, Kylie. "People, Places ... And Other People? Integrating Understanding of Intrapersonal, Social and Environmental Determinants of Physical Activity." Journal of Science and Medicine in Sport 9, no. 5 (2006): 367-70.

Ball, Kylie, Anna Timperio, Jo Salmon, Billie Giles-Corti, Rebecca Roberts, and David Crawford. "Personal, Social and Environmental Determinants of Educational Inequalities in Walking: A Multilevel Study." Journal of Epidemiology and Community Health 61, no. 2 (2007): 108-14.

Bandura, Albert. "Social Cognitive Theory: An Agentic Perspective." Annual Review of Psychology 52 (2001): 1-26. . "Swimming against the Mainstream: The Early Years from Chilly Tributary to Transformative Mainstream." Behaviour Research and Therapy 42 (2004): 613-30.

Beeson, Diane. "Nuance, Complexity, and Context: Qualitative Methods in Genetic Counseling Research." Journal of Genetic Counseling 6, no. 1 (1997): 21-43.

Bellows-Riecken, Kai H., and Ryan E. Rhodes. "A Birth of Inactivity? A Review of Physical Activity and Parenthood." Preventive Medicine 46, no. 2 (2008): 99110.

Biddle, Stuart H., and Nanette Mutrie. Psychology of Physical Activity Determinants, Well-Being and Interventions. 2nd ed. Abingdon: Routledge, 2008.

Braun, Virginia, and Victoria Clarke. "Using Thematic Analysis in Psychology." Qualitative Research in Psychology, no. 3 (2006): 77-101.

Brayton, Jennifer "What Makes Feminist Research Feminist? The Structure of Feminist Research within the Social Sciences." http://www.unb.ca/PARL/win/feminmethod.htm.

Bronfenbrenner, Uri. Making Human Beings Human: Bioecological Perspectives on Human Development. Thousand Oaks: Sage Publications Inc, 2005.

Brooks, Fiona, and Josetine Magnusson. "Physical Activity as Leisure: The Meaning of Physical Activity for the Health and Well-Being of Adolescent Women." Health Care for Women International 28, no. 1 (2007): 69-87.

Brown, Wendy J., and Stewart G. Trost. "Life Transitions and Changing Physical Activity Patterns in Young Women." American Journal of Preventive Medicine 25, no. 2 (2003): 140-43.

Callister, Paul. "The Changing Gender Distribution of Paid and Unpaid Work in New Zealand." Wellington, 2005.

Caspersen, C. J., K. E. Powell, and G. M. Christenson. "Physical Activity, Exercise, and Physical Fitness: Definitions and Distinctions for Health Related Research." 126-31: Public Health Reports 100, 1985. 
Centers for Disease Control and Prevention, CDC. "Physical Activity and Health: A Report of the Surgeon General." edited by Division of Nutrition and Physical Activity, 1999.

Crotty, Michael. The Foundations of Social Research. Crows Nest, NSW: Allen \& Unwin, 1998.

Dacey, Marie, Amy Baltzell, and Len Zaichkowsky. "Factors in Women's Maintenance of Vigorous or Moderate Physical Activity." Women in Sport \& Physical Activity Journal 12, no. 1 (2003).

Davidson C, and Tolich M. Social Science Research in New Zealand Edited by Pearson. Second ed. Auckland: Pearson Education New Zealand Limited., 2003.

Eyler, Amy E., Elizabeth Baker, LaChenna Cromer, Abby C. King, Ross C. Brownson, and Rebecca J. Donatelle. "Physical Activity and Minority Women: A Qualitative Study." Health Education \& Behaviour 25, no. 5 (1998): 640-52.

Eyler, Amy E., Sara Wilcox, Dyann Matson-Koffman, Kelly R. Evenson, Bonnie Sanderson, Janice Thompson, JoEllen Wilbur, and Deborah Rohm-Young. "Correlates of Physical Activity among Women from Diverse Racial/Ethnic Groups." Journal of Women's Health \& Gender-Based Medicine 11, no. 3 (2002): 239-53.

Fereday, J., and E. Muir-Cochrane. "Demonstrating Rigor Using Thematic Analysis: A Hybrid Approach of Inductive and Deductive Coding and Theme Development." International Journal of Qualitative Methods 5, no. 1 (2006): Article 7.

Garrett, Robyne. "Negotiating a Physical Identity: Girls, Bodies and Physical Education." Sport, Education and Society 9, no. 2 (2004): 223-37.

Gidlow, B., and G Cushman. "Bringing Men Back In? Male Recreational Hunters, Divers and Fly-Fishers and the Creation of Recreational Space." Annals of Leisure Research 11, no. In press (2008).

Giles-Corti, Billie, and Robert J. Donovan. "The Relative Influence of Individual, Social and Physical Environment Determinants of Physical Activity." Social Science \& Medicine 54, no. 12 (2002): 793-812.

Gilligan, Carol. In a Different Voice. Cambridge: Harvard University Press, 1982. . "Moral Orientation and Moral Development." In Women and Moral Theory, edited by Eva Feder Kittay and Diana T. Meyers. Totowa: Rowman \& Littlefield, 1987.

Green Eileen, Sandra Hebron, and Woodward Diana. Women's Leisure, What Leisure? Houndmills: Macmillan Education Ltd., 1990.

Hamilton-Smith, Elery. "Work, Leisure and Optimal Experience." Leisure Sciences, no. 11 (1992): 243-56.

Harding, Sandra. "Is There a Feminist Method?" In Feminism \& Methodology, edited by Sandra Harding. Bloomington: Indiana University Press, 1987.

Haughton-McNeill, Lorna, Matthew W. Kreuter, and S.V. Subramanian. "Social Environment and Physical Activity: A Review of Concepts and Evidence." Social Science \& Medicine, no. 63 (2006a): 1011-22.

Haughton-McNeill, Lorna, Kathleen W. Wyrwwich, Ross C. Brownson, Eddie M. Clark, and Matthew W. Kreuter. "Individual, Social Environmental, and Physical Environmental Influences on Physical Activity among Black and White Adults: A Structural Equation Analysis." Annals of Behavior Medicine 31, no. 1 (2006b): 36-44. 
Haworth, John T. Work, Leisure and Well-Being. London: Routledge, 1997.

Haywood Les. "Dimensions of Leisure." In Understanding Leisure. Cheltenham: Stanley Thornes, 1995.

Henderson, Karla A. "Enhancing Women's Physical Activity Involvement." Women in Sport \& Physical Activity Journal 7, no. 1 (1998).

. "One Size Doesn't Fit All: The Meaning of Women's Leisure." Journal of Leisure Research Summer (1996).

_. "Women, Physical Activity, and Leisure: Jeopardy or Wheel of Fortune?" Women in Sport \& Physical Activity Journal 12, no. 1 (2003b): 113.

Henderson, Karla A., and M. Deborah Bialeschki. "Inclusive Physical Activity Programming for Girls and Women." Parks and Recreation 30, no. 3 (1995): 70-78.

Henderson, Karla A., M. Deborah Bialeschki, Susan Shaw, and Valeria Freysinger. Both Gains and Gaps: Feminist Perspectives on Women's Leisure. State College: Venture Publishing Inc, 1996.

Hiles, David, and Ivo Cermak. "Qualitative Research: Transparency and Narrative Oriented Inquiry." In X European Congress of Psychology. Prague, CZ, 2007.

Im, Eun-Ok, Wonshik Chee, Hyun-Ju Lim, Yi Liu, and Hee Kyung Kim. "Midlife Women's Attitudes toward Physical Activity." Journal of Obstetric, Gynecologic, \& Neonatal Nursing 37, no. 2 (2008): 203-13.

Jenkins, Carolyn, Phil Handcock, Lisette Burrows, and Ken Hodge. "Exercise Barriers Faced by First-Time Mothers." New Zealand College of Midwives (Inc) 35 (2006): 8-11.

Kitzinger, Jenny. "The Methodology of Focus Groups: The Importance of Interaction between Research Participants." Sociology of Health and Illness 16, no. 1 (1994).

. "Qualitative Research: Introducing Focus Groups." British Medical Journal 311, no. 7000 (1995): 299-302.

Knox, Elizabeth. Billie's Kiss. Wellington: Victoria University Press, 2002.

Krueger, Richard A. The Focus Group Kit, 6. Thousand Oaks: Sage Publications Inc., 1998.

Krueger, Richard A., and Mary Anne Casey. Focus Groups Second Edition: A Practical Guide for Applied Research. Thousand Oaks: Sage Publications Inc., 2000.

Leith, Denise, and Susan Shaw. "Physical Inactivity in Leisure: Why Some Women Adopt Inactive Lifestyles." Journal of Applied Recreation Research 22, no. 4 (1997): 339-64.

Letherby, Gayle. Feminist Research in Theory and Practice. Buckingham: Open University Press, 2003.

Lewis, Belinda, and Damien Ridge. "Mothers Reframing Physical Activity: Family Oriented Politicism, Transgression and Contested Expertise in Australia." Social Science \& Medicine 60 (2005): 295-306.

Lewis, Melinda. "Focus Group Interviews in Qualitative Research: A Review of the Literature." (2000), http://www2.fhs.usyd.edu.au/arow/arer/pdf\%20eReport\%20version/002.pdf.

Mannell, Roger C. "Encyclopedia of Leisure and Outdoor Recreation." In Encyclopedia of Leisure and Outdoor Recreation, edited by John M. Jenkins and John J. Pigram. London: Routledge, 2003. 
Marcus, Bess H., and Leigh Ann H. Forsyth. "Tailoring Interventions to Promote Physically Active Lifestyles in Women." Women's Health Issues 8, no. 2 (1998): 104-11.

McElroy, Mary. Resistance to Exercise: A Social Analysis of Inactivity. Edited by Human Kinetics. Champaign: Kansas State University, 2002.

Mclaren, Lindsay, and Penelope Hawe. "Ecological Perspectives in Health Research." Journal of Epidemiology and Community Health 59 (2005): 6-14.

McLean, Grant, and Marinka Teague. "Obstacles to Action: A Study of New Zealanders Physical Activity and Nutrition." In Social Policy and Research and Evaluation Conference. Wellington, New Zealand, 2004.

Miller, Yvette D., and Wendy J. Brown. "Determinants of Active Leisure for Women with Young Children - An "Ethic of Care" Prevails." Leisure Sciences 27, no. 5 (2005): 405-20.

Morgan, David L. Focus Groups as Qualitative Research. Thousand Oaks: Sage Publications Ltd., 1997.

- Successful Focus Groups: Advancing the State of the Art. Newbury Park: Sage, 1993.

Mutrie, Nanette, and Precilla Y. L. Choi. "Is 'Fit' a Feminist Issue? Dilemmas for Exercise Psychology." Feminism Psychology 10, no. 4 (2000): 544-51.

Nomaguchi, Kei M., and Suzanne M. Bianchi. "Exercise Time: Gender Differences in the Effects of Marriage, Parenthood, and Employment." Journal of Marriage and Family 66, no. 2 (2004): 413-30.

OECD, Organisation for Economic Development and Cooperation. "Special Focus: Measuring Leisure in O.E.C.D Countries." In Society at a Glance: OECD Social Indicators, 2009.

Park, Robert E., Ernest W. Burgess, and Roderick D. McKenzie. The City. Chicago: The University of Chicago Press, 1925.

Patton, Michael Q. Qualitative Research and Evaluation Methods. 3rd ed. Thousand Oaks: Sage Publications Inc., 2002.

Phongsavan, Philayrath, McLean Grant, and Adrian Bauman. "Gender Differences in Influences of Perceived Environmental and Psychosocial Correlates on Recommended Level of Physical Activity among New Zealanders." Psychology of Sport and Exercise 8, no. 6 (2007): 939-50.

Pope, Catherine, Nicholas Mays, and Jennie Popay. Synthesizing Qualitative and Quantitative Health Research. Maidenhead: Open University Press, 2007.

Prosser, Rachel A., Anne C. Thomas, and Cynthia S. Darling-Fisher. "Physical Activity Intervention in an Academic Setting: Focus Group Results." American Association of Occupational Health Nurses Journal 55, no. 11 (2007): 448.

Research Methods in the Social Sciences. Edited by B Somekh and C Lewin. Thousand Oaks: Sage, 2005.

Rubin, Herbert J., and Irene S. Rubin. Qualitative Interviewing: The Art of Hearing Data Second Edition. Thousand Oaks: Sage Publications Inc, 2005.

"The Sage Encyclopedia of Social Science Research Methods." edited by M.S. Lewis-Beck, A. Bryman and Tim Futing Liao. Thousand Oaks: Sage Publications Inc, 2004.

The Sage Handbook of Qualitative Research Edited by Norman K. Denzin and Yvonna S. Lincoln. Third ed. Thousand Oaks: Sage Publications Inc., 2005. 
Sallis, James F., Adrian Bauman, and Michael Pratt. "Environmental and Policy Interventions to Promote Physical Activity." American Journal of Preventive Medicine 15, no. 4 (1998): 379-97.

Sallis, James F., Adrian Bauman, and Michael Pratt. "Environmental and Policy Interventions to Promote Physical Activity." American Journal of Preventive Medicine 15, no. 4 (1998): 379-97.

Segar, M., J. S. Eccles, S. C. Peck, and C. R. Richardson. "Midlife Women's Physical Activity Goals: Sociocultural Influences and Effects on Behavioral Regulation." Sex Roles 57 (2007): 837-49.

Segar, Michelle, Toby Jayaratne, Jennifer Hanlon, and C. R. Richardson. "Fitting Fitness into Women's Lives: Effects of a Gender-Tailored Physical Activity Intervention." Women's Health Issues 12, no. 6 (2002): 338-47.

Shaw, Susan M. "Conceptualizing Resistance: Women's Leisure as Political Practice." Journal of Leisure Research 33, no. 2 (2001): 186-201.

Skowron, Maya A., Monika Stodolska, and Kimberly J. Shinew. "Determinants of Leisure Time Physical Activity Participation among Latina Women." Leisure Studies 30 (2008): 429-27.

Sparling, Phillip B., Neville Owen, Estelle V. Lambert, and William L. Haskell. "Promoting Physical Activity: The New Imperative for Public Health." Health Education Research 15, no. 3 (2000): 367-76.

Sport and Recreation New Zealand, SPARC. "Activity Friendly Environments." http://www.sparc.org.nz/partners-and-programmes/active-communities/activefriendly-environments/what-is.

. "Changing Physical Activity Behaviour: Key Lessons Learned from Regional and District Physical Activity Strategies." http://www.sparc.org.nz/filedownload?id=8c988113-02cd-4fc7-a59af36d6316e6ec.

. "Push Play -Overview." http://www.sparc.org.nz/pushplay-oveview. . "Sport, Recreation and Physical Activity Participation among New Zealand Adults: Key Results of the 2007/08 Active New Zealand Survey." Place Published, 2008.

State Services Commission. "Crown Entities." http://www.ssc.govt.nz/display/home.asp.

Sullivan, Charles, Judy Oakden, Hugh Butcher, Suprita Bharti, and Steve Moore. "Obstacles to Action: A Study of New Zealanders' Physical Activity and Nutrition Overview Report." In Obstacles to Action: A Study of New Zealanders' Physical Activity and Nutrition, edited by A.C. Neilsen. Wellington, 2003. . "Obstacles to Action: A Study of New Zealanders' Physical Activity and Nutrition Profiling Busy and Stressed." 2006.

Tavares, L. S., and R. C. Plotnikoff. "Not Enough Time? Individual and Environmental Implications for Workplace Physical Activity Programming among Women with and without Young Children." Health Care for Women International 29, no. 3 (2008): 244-81.

Thompson, Shona. "Woman and Leisure in Aotearoa/New Zealand and Australia." In Time Out? Leisure, Recreation and Tourism in New Zealand and Australia, edited by G Cushman and Harvey C. Perkins. Auckland: Addison Wesley Longman, 1998.

Tong Putnam, Rosemarie. Feminist Thought: A More Comprehensive Introduction. Second ed. Boulder: Westview Press, 1998. 
Trost, Stewart G., Neville Owen, Adrian Bauman, James F. Sallis, and Wendy J.

Brown. "Correlates of Adults' Participation in Physical Activity: Review and Update." Medicine \& Science in Sports \& Exercise 34, no. 12 (2002): 19962001.

Tudor-Locke, Catrine, Karla A. Henderson, Sara Wilcox, Rhonda S. Cooper, Larry J. Durstine, and Barbara Ainsworth. "In Their Own Voices: Definition and Interpretations of Physical Activity." Women's Health Issues, no. 13 (2003): 194-99.

Urban Walker, Margaret "What Does the Different Voice Say?: Gilligan's Women and Moral Philosophy." The Journal of Value Inquiry 23 (1989): 123-34.

Verhoef, M. J., E. J. Love, and M. S. Rose. "Women's Social Roles and Their Exercise Participation." Women and Health 19, no. 4 (1992): 15-29.

Vertinsky, Patricia. "Run Jane, Run: Central Tensions in the Current Debate About Enhancing Women's Health through Exercise." Women \& Health 27, no. 4 (1998): 81-111.

Victoria University of Wellington, VUW. "Human Ethics Committee Guidelines." http://policy.vuw.ac.nz/Amphora! policy.vuw.ac.nz POLICY 0000000019 58.pdf.

Vrazel, JoEllen, Ruth P. Saunders, and Sara Wilcox. "An Overview and Proposed Framework of Social-Environmental Influences on the Physical-Activity Behavior of Women." American Journal of Health Promotion 23, no. 1 (2008): 2-12.

Wolf, Naomi. "From Lady Di to Michelle Obama." Dominion Post, 5 March 2009.

World Health Organisation, WHO. "Physical Activity." http://www.who.int/topics/physical_activity/en/. 